Portland State University

PDXScholar

\title{
Adult English as A Second Language Literacy Programs in the Non-profit Sector of Multnomah County, Oregon
}

Susan Edna Binford

Portland State University

Follow this and additional works at: https://pdxscholar.library.pdx.edu/open_access_etds

Part of the Bilingual, Multilingual, and Multicultural Education Commons Let us know how access to this document benefits you.

Recommended Citation

Binford, Susan Edna, "Adult English as A Second Language Literacy Programs in the Non-profit Sector of Multnomah County, Oregon" (1994). Dissertations and Theses. Paper 4704.

https://doi.org/10.15760/etd.6588

This Thesis is brought to you for free and open access. It has been accepted for inclusion in Dissertations and Theses by an authorized administrator of PDXScholar. Please contact us if we can make this document more accessible: pdxscholar@pdx.edu. 


\section{THESIS APPROVAL}

The abstract and thesis of Susan Edna Binford for the Master of Arts in Teaching English to Speakers of Other Languages were presented May 2, 1994, and accepted by the thesis committee and the department.

COMMITTEE APPROVALS:
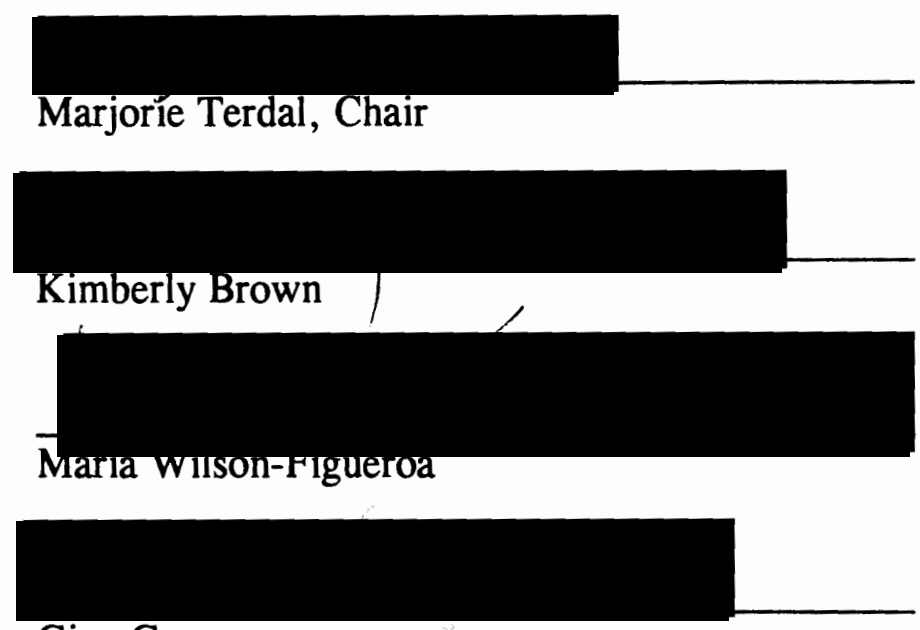

Gina Greco

Representative of the Office of Gradute Studies

DEPARTMENT APPROVAL:

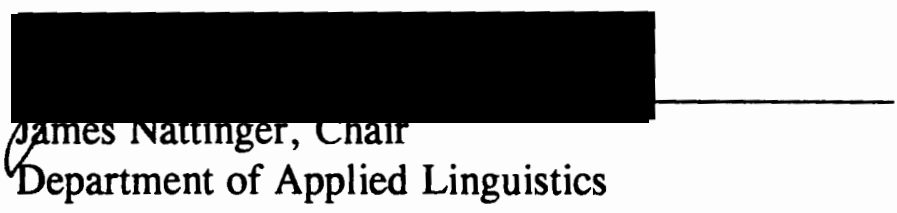

$* * * * * * * * * * * * * * * * * * * * * * * * * * * * * * * * * * * * * * * * * * * * * * * * * * * * * * * * * * * * * * * * * * * * * * * * * *$

\section{ACCEPTED FOR PORTLAND STATE UNIVERSITY BY THE LIBRARY}

by on

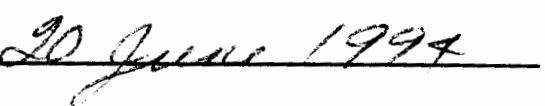




\begin{abstract}
An abstract of the thesis of Susan Edna Binford for the Master of Arts in Teaching English to Speakers of Other Languages presented May 2, 1994.
\end{abstract}

Title: Adult English as A Second Language Literacy Programs in the Non-profit Sector of Multnomah County, Oregon.

The present study identified and described the general education English as a Second Language (ESL) programs in Multnomah County, Oregon, offered by nonprofit organizations, in order to promote a more coordinated effort to meet the needs of the community. The study asked the following questions: 1) What are the non-profit organizations providing general adult ESL instruction in Multnomah County, Oregon?;

2) What are the nature and characteristics of these adult ESL education programs, including methods of recruiting, assessing, and tracking students?; 3) What are the methods of recruiting, training, and tracking volunteer teachers?; and 4) What, if any, ESL resource services made available would be perceived as most beneficial to this sector of the ESL instructional community?

There were three parts to the study: 1) identifying the organizations, conducted by using an exploratory approach; 2) structured telephone interviews; and 3) classroom observations and/or teacher interviews, conducted by using ethnographic techniques with a stratified sample derived from the analysis of the data generated in the second portion of the research. 
Fourteen organizations qualified for the study, serving approximately 428 students. Methods of student recruitment were most commonly by word of mouth and referral or refugee assignment. Very few formal means of student evaluation and tracking of educational progress were reported. All ESL instruction was found to be performed by approximately 185 volunteers, recruited most frequently by word of mouth. Volunteers were most commonly trained by attending volunteer training seminars and/or receiving prepared handouts, or by no training at all. Tracking was done by telephone, forms, or not at all. The services perceived most valuable, listed from most to least, were: tutor training seminars, instructional material recommendations, grant and funding information, recruitment of volunteer tutors, and recommendations on methods of student evaluation. Student evaluation was the only service rated less than valuable.

A mailing list was created from the information generated from the telephone interviews and forwarded to Portland Community College, and The Portland Literacy Council, whose information has been updated accordingly. 


\title{
ADULT ENGLISH AS A SECOND LANGUAGE LITERACY PROGRAMS IN THE
} NON-PROFIT SECTOR OF MULTNOMAH COUNTY, OREGON

\author{
by \\ SUSAN EDNA BINFORD
}

A thesis submitted in partial fulfillment of the requirements for the degree of

\section{MASTER OF ARTS}

in

TEACHING ENGLISH TO SPEAKERS OF OTHER LANGUAGES

\author{
Portland State University \\ 1994
}




\section{ACKNOWLEDGMENTS}

I owe a special debt to my thesis advisor Marjorie Terdal for her unfailing support and assistance throughout this project. The study has been improved considerably by her recommendations and criticisms. I am very grateful for the time she has spent, and for the encouragement, direction and advice she has given. I would also like to thank all of my committee members for their comments and suggestions during the learning process which has occurred in both my course work and this thesis project.

My very special thanks are to all of my friends and family members who have been supportive and understanding throughout my work. I would especially like to thank my brother Tom Binford, and my friends Larry Brown and John Pellet for the 24 hour-a-day computer support service/counseling.

Finally, I would like to thank all of the people involved in adult ESL education with whom I have had the privilege and pleasure of meeting while working on this project. You have been a continual source of inspiration and I wish to thank you for allowing me to study the admirable work that you are doing. 


\section{TABLE OF CONTENTS}

PAGE

ACKNOWLEDGMENTS

v

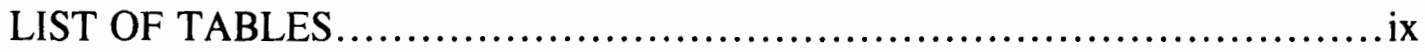

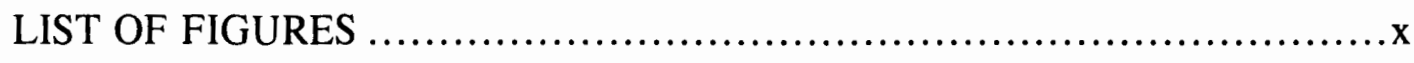

CHAPTER

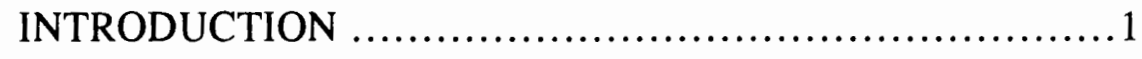

Definition of Terms ................................... 4

Summary ............................................. 5

II REVIEW OF THE LITERATURE ......................... 7

Adult ESL Literacy Education: A Brief Historical

Recount .......................................... 7

Adult ESL Literacy Today ..............................11

Classifying Literacy Practices

Instructional Approaches

Program Recommendations from Research Findings .......18

The Role of Volunteers..................................21

Recruitment

Interviewing, Placement and Orientation

Training

Record Maintenance

Adult ESL Literacy Students ..........................24

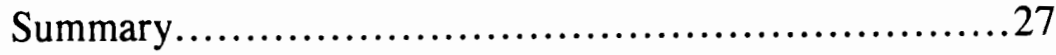

III RESEARCH METHOD.....................................29 
Identification of the Organizations .........................29

Program Coordinator Telephone Interviews................30

Mailing List Information

Nature and Characteristics of the Program

Support Service Needs Evaluation

Teacher/Tutor Interviews and Instructional Observations ..35

Limitations of the Research Method .........................36

Summary............................................. 37

IV RESEARCH FINDINGS .................................. 38

Identification of the Organizations ........................38

Program Coordinator Telephone Interviews................39

Mailing List Information

Nature and Characteristics of the Program

Rating Practices to Educational Objectives

Rating the Value of Support Services Made Available

Detailed Organization Profiles...........................6 63

Organization $\mathrm{C}$

Organization $\mathrm{G}$

Organization U

Organization Y

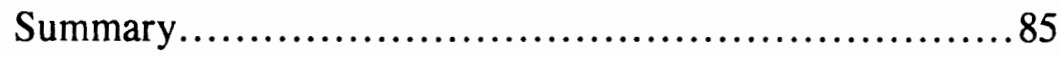

V CONCLUSION ........................................... 88

Discussion of Results .................................. 88

Research Question Number 1

Research Question Number 2

Research Question Number 3

Research Question Number 4

Recommendations for Researchers and Practitioners.......93

Suggestions for Additional Research .....................96 
Summary

REFERENCES .98 APPENDICES

A MAILING LIST OF PARTICIPATING 


\section{LIST OF TABLES}

TABLE

PAGE

I Results from Calls Made to Identify Organizations ...............39

II Types of Services Offered ..................................44

III Attendance Averages by Groups Shown in Months...............46

IV Methods of Student Recruitment...............................47

V Methods of Initial Student Assessment..........................49

VI Methods of Tracking Students' Educational Progress .............50

VII Number of Volunteer Tutors and Teachers by Group .............51

VIII Methods of Recruiting Volunteers by Group ..................55

IX Criteria for New Volunteers..................................55

$\mathrm{X} \quad$ Volunteer Training Methods ................................55

XI Methods of Tracking Volunteers ............................57

XII Average Rating of Practice to Objective ........................58

XIII Average Rated Value of Support Services Made Available ......61 


\section{LIST OF FIGURES}

1. Length of ESL Service in Years................................41

2. Average Length of Student Attendance in Months...............44

3. Average Rating of Practice to Objective for Group I ............59

4. Average Rating of Practice to Objective for Group II ............59

5. Average Rated Value of Support Services Made Available for Group I .........................................62

6. Average Rated Value of Support Services Made Available for Group II .........................................62 


\section{CHAPTER I}

\section{INTRODUCTION}

The purpose of the study reported here was to identify and describe those adult literacy English as a Second Language (ESL) programs in Multnomah County, Oregon, offered by non-profit organizations, in order to promote a more coordinated effort to meet the needs of the community. This target group of programs offers ESL services in the form of general English education. This means that the focus of education is on

the increased ability to communicate in English, be it by written or verbal means. It was believed that there possibly existed a gap between the information and services generated on the national and state level and the ESL literacy education providers in the non-profit organization sector.

In July of 1991, the National Literacy Act of 1991 was signed into enactment. The purpose of this act was to aid in enhancing basic and literacy skills of adults in order to ensure that all adults in the United States would be able to "function effectively and achieve the greatest possible opportunity in their work and in their lives, and to strengthen and coordinate adult literacy programs" (National Literacy Act, 1991, p. 1). This act was prompted by several conclusions as a result of an extensive national study. Some of the conclusions are summarized below:

Nearly $30,000,000$ adults in the United States have serious problems with literacy.

Literacy is thought to be intergenerational and closely associated with poverty. 
The prevention of illiteracy is necessary to curb increased growth in illiteracy rates, posing a major threat to the well-being of the United States.

All public and private literacy programs serve only approximately 19 per cent of those who need help, and often there are only minimal gains within these programs.

Literacy programs usually lack adequate funding, coordination with other literacy programs, and investment in teacher training and technology. (National Literacy Act, 1991)

This act nearly doubled the amount of Federal funds budgeted to improve assistance to state and local adult literacy education. In addition to authorizing and improving specific literacy programs, the provisions of this Act included establishing The National Institute for Literacy, whose purpose is to "advance and support research and promote good practices" (Irwin, 1991, p. 5). In order to better facilitate the delivery system to local service providers, state grants were awarded to create State Literacy Resource Centers. These Centers were established to "stimulate the coordination of literacy resources" (Irwin, 1991, p. 5).

This multi-level delivery system was believed to be conducive to the possibility of a break-down in the delivery of information generated and transmitted to the local ESL service providers within the non-profit sector. Preliminary information gathered by the researcher indicated that the ESL service providers within this sector had not been systematically identified, nor described. It was postulated that by identifying, describing and making available this information, a more coordinated effort between the state and local levels of ESL service providers could be achieved. It was also hoped that the sharing of information would be a catalyst for increased communication, and for creating a support network among the identified organizations themselves.

Flemming (1984) performed a study of the ESL programs in Northern New England, inquiring into the nature of such programs being offered in Maine, New 
Hampshire, and Vermont. He found that although there were present in each area a substantial amount of information and professional services available to the community, often those providing ESL services were not accessing this information. The author notes:

It would appear that there is a good deal of "reinventing the wheel" in ESL instruction in Northern New England. Among the reasons are that many ESL teachers are isolated, working with only a few students, and are not adequately supported by colleagues or superiors.

The need for ESL instruction is often considered a "crisis" by regular staff members and administrators. If these individuals know where to turn, they will seek help, but they often will not maintain the kind of support necessary to make a program successful.

There is, in each of the three states, the potential for an adequate support network and a sufficient supply of experts to provide consulting services. The need is to make these resources known to the people in positions of responsibility so that they in turn can provide information and contacts to the ESL professionals in the field. (p. 19)

It was believed that a similar situation may exist in the Portland, Oregon area. The focus of this study was on those ESL instruction providers not formally linked to the State program and network. This study asked the following questions:

What are the non-profit organizations providing general adult ESL instruction in Multnomah County, Oregon?

What are the nature and characteristics of these adult ESL education programs, including methods of recruiting, assessing and tracking students?

What are the methods of recruiting, training and tracking volunteer teachers?

What, if any, ESL resource services made available would be perceived as most beneficial to this sector of the ESL instructional community? 
The research method chosen for this study was a descriptive case study. There were three parts to the study, and each part employed a different technique of gathering data. The first part, identifying the organizations, was conducted by using an exploratory approach. An initial call list of possible organizations was compiled and these organizations were contacted by telephone to determine whether they offered ESL services. Also, as an on-going process, all organizations contacted were asked if they knew of other ESL service providers within the area of Multnomah County, Oregon. The second part of the study, structured telephone interviews, was conducted with the coordinators of the programs whose organizations qualified for the study. The data generated from the telephone interviews were then analyzed and classified into two groups. Based on these groups, a stratified sample of two programs from each group was selected, and the third portion of the study, classroom observations and/or teacher interviews, was conducted using ethnographic techniques.

A mailing list was created from the information generated from the telephone coordinator interviews of those organizations interested in receiving additional information pertaining to the improved implementation of services and/or creating a support network. This list was forwarded to the Volunteer Coordinator at Portland Community College (PCC), and also to the Portland Literacy Council, whose information has been updated accordingly. These two organizations expressed an interest in the results of this study, and were consulted throughout the research.

\section{DEFINITION OF TERMS}

Literacy - definitions are often a political act, reflecting the current beliefs of a given society. For the purpose of this study, literacy is defined consistent with the National Literacy Act of 1991, which defines literacy as "an individual's ability to read, write, and speak in English, and compute and solve problems at levels of 
proficiency necessary to function on the job and in society to achieve one's goals and develop one's knowledge and potential" (National Literacy Act, 1991, p. 1).

Adult ESL literacy program - refers to any program designed to educate or train a non-native English speaking adult (roughly 18 years or older) in order to achieve those proficiencies stated in the National Literacy Act of 1991. For the purpose of this study, vocational ESL has not been included within this definition.

Non-profit organization - is used to distinguish those organizations which are private, non-profit, non-governmental entities. Those organizations studied within this research are either community-based or church-based organizations.

ESL support services - refers to those services which aid in the process of delivering ESL instruction. These may include, for example, initial and in-service training, educational materials, curriculum design, or grant funding.

Tutor - is the term used to refer to an ESL instructor who is teaching one student or a small group of roughly four or less students. Normally a tutor is a volunteer.

Teacher - is the term used to identify those ESL instructors working with groups in a classroom situation. Teachers can be volunteers, or full or part-time paid employees.

\section{SUMMARY}

The purpose of the study reported here was to identify and describe those adult ESL literacy programs in Multnomah County, Oregon, offered by non-profit organizations, in order to promote a more coordinated effort to meet the needs of the community. Chapter 2 presents a review of the literature relevant to the issues of adult ESL education. Chapter 3 details the research method chosen and designed to conduct 
this descriptive case study. A report of the research findings follows within Chapter 4 . Finally, Chapter 5 concludes the report with a discussion of the results, recommendations to those involved in adult ESL education, and suggestions for additional research. 


\section{CHAPTER II}

\section{REVIEW OF THE LITERATURE}

This chapter opens with a brief history of the adult literacy movement in the United States beginning at the turn of the century. A discussion of national trends in early adult literacy programs is presented in order to illustrate the progression of the field of adult ESL literacy, and also to describe the basis for the diversity of programs found in existence today. Following the history, a discussion of the ESL literacy practices of today ensues, presenting current beliefs and practices, with an explanation of six basic philosophical underpinnings of literacy curricula, and also six instructional approaches to ESL adult literacy education. Next presented are recommendations for successful programs, gathered from the research of model ESL adult literacy programs. The role of the volunteer is then discussed, specifically, motivational factors for volunteers, and necessary steps to administer volunteer programs. The chapter concludes with a presentation of adult ESL literacy learners, discussing their possible goals, motivations, and program recommendations.

\section{ADULT ESL LITERACY EDUCATION: A BRIEF HISTORICAL RECOUNT}

One of the interesting characteristics of ESL literacy programs is the diversity of programs; that is programs are being conducted and/or funded through the local, state and federal levels of government. Programs exist in both the private and public sectors, and in the non-profit and profit based sectors as well. This was not always the case. Prior to the $1900^{\prime}$ s, literacy was not viewed as a national issue. Immigration policies at that time did not use literacy as a requirement for entry into the United 
States, nor as a naturalization criterion (McKay \& Weinstein-Shr, 1993). At that time, the United States was focused on expansion in its various forms. The push for industrialization and the development of transportation and communication networks saw an increase in the non-English speaking and often illiterate immigrant population. This population formed an economically popular supply of unskilled labor, available to accomplish the task of national expansion (Cook, 1977).

The expansion effort created a large, non-English speaking population who, after the efforts had subsided, were in competition with the existing labor force. The result was a climate of intolerance and a push towards reducing the intake of new immigrants, and "Americanizing" those who were already in the United States. Wiley (1993) describes the climate of the period as follows:

powerful factions within the dominant society took opposing stances with respect to the imposition of immigration-related literacy requirements. Nativists, who sought racial, cultural, and linguistic dominance, battled industrialists, who wanted cheap labor through open immigration policies. Trade unionists, who feared being undercut by a steady flow of cheap foreign labor, found themselves allied with nativists. (p. 423)

Thus in the early 1900 's legislation with literacy requirements began to be initiated to restrict immigrant intake, and there began to appear special interest groups with specific motivations for educating the illiterates. Local programs were initiated by groups such as labor unions, industrial management, and specific communities (Cook, 1977).

The United States' involvement in World War I, beginning approximately in 1916, gave rise to an increased anti-foreign born sentiment. It also brought to light the fact that $25 \%$ of the men drafted could not read a newspaper or write a letter. Cook (1977) states that these two factors affected literacy in two ways. The first was an attempt to minimize foreign influence within the country. Legislation was passed to restrict immigration of those sixteen years or older who could not read in any language, 
and with the intensified focus of "Americanization", English was the only language taught in schools.

Second, adult literacy programs began to appear on the state and local levels in order to educate potential military personnel. It was during this period that the Kentucky Moonlight School, often attributed to being the first adult literacy program in the United States, was created. The popularity of this program spread, and volunteers were trained to teach in the new programs established in surrounding counties. The next several years showed an increase in moonlight schools in several states. The schools worked closely with the wartime efforts, educating potential enlisted men, and also family members of those overseas in order to increase correspondence and morale (Cook, 1977).

The advances in military technology used in World War II demanded a largely literate work force. In 1941, enlistment requirements were defined to exclude any individuals not displaying a fourth grade proficiency in reading and writing. After four months, 140,000 applicants had been rejected: 3.8 percent of the Caucasian applicants, and 11.2 per cent of the Afro-American applicants. As the demand for more soldiers increased, and at home the male population between the ages of 20 to 44 shifted to an illiterate, minority population, the literacy standards were continually lowered until in 1943, applicants were permitted to pass the intelligence test by either written or oral means. The army was therefore forced to educate the illiterate enlisted men. Thus, the Federal government became involved in literacy education, and the established army literacy program was, up to that date, the most extensive, largest, and best financed adult literacy program in the United States (Cook, 1977).

The 1950's saw an increase in technological demands which were perceived to mandate an increased adult literacy standard. What was once considered a state and local problem, was now considered a national burden. Emphasis was placed on 
volunteer and teacher training, and graduate and undergraduate teacher education programs began to be developed (Cortright, 1961).

The literacy movement continued to expand in the 1960's, and "for the first time active participation of the federal government yielded legislation backed with financial support. It was now possible to carry out extensive programs, train teachers, and prepare materials" (Cook, 1977, p. 103). Literacy began to be seen in terms of functional literacy, and from this idea emerged the shift to providing education not only in reading and writing, but in skills to better enable the learner to function in the everincreasing technologically advanced world. Research began to flourish in the area of literacy, and professional publications were created to disperse the increasing information generated by research in the areas of materials development, teaching techniques, literacy teacher training, and background reading.

The adult literacy movement was greatly affected in the 1970's, by the large influx of refugee arrivals. Until this time, immigrant populations in the United States had decreased as immigration requirements had become increasingly demanding. Rowekamp (no date) states

English language education for immigrants continued throughout the first two-thirds or so of the century, but on a very small scale and generally in association with an adult education program serving native English speaking Americans who needed assistance in acquiring literacy skills and/or high school equivalency diplomas (Graduate Equivalency Diplomas or GEDs). The teachers of such ESL classes were generally not specifically trained in teaching ESL or adults but were most often elementary or secondary teachers. (p. 2)

Developing as a profession of its own in the 1960's, ESL, once primarily geared toward the academic system, now began to broaden its scope to include the education of adult literacy students. It was during this period that adult ESL began to be recognized as a unique field. 


\section{ADULT ESL LITERACY TODAY}

Traditionally the Federal Government's involvement in refugee resettlement has been "often viewed as a short-term process if not in actuality, then at least as an ideal" (Haines, 1985, p. 37), whose goal is to provide language skills which will enable the refugee to make an expedient transition to self-sufficiency. This attitude is also reflected in the volunteer agencies contracted to sponsor refugees. As a national guideline, the Church World Service (Brewer \& Taran, 1992) states "according to the Refugee Act of 1980 , a primary objective of resettlement is the financial and social self-sufficiency of the refugees" (p. 29). On the local level, volunteer sponsor agencies, as noted in the Handbook for Refugee Sponsorship (Smith, 1991) write:

It is important to note, however, that finding a job is not dependent upon language ability. There are many jobs which can be performed adequately without knowledge of English. In many cases, too, English skills improve markedly once the refugee is on the job and begins to hear and use English on a daily basis. (p. 4)

The initial emphasis for adult ESL classes in many cases by the groups associated with the resettlement process of refugees and immigrants has been, and remains to be, focused on a short-term language training model stressing the skills necessary to obtain rapid employment and therefore economic self-sufficiency.

Criticism of this short term approach to language training began to be heard in the mid 1980's (see, for example, Auerbach \& Burgess, 1985; Tollefson, 1988). The short term approach to language training often finds the learner unable to obtain more than marginal, entry-level employment, with little chance for upward mobility. Tollefson (1991) argues:

while about a fifth of all refugee families live above the poverty line after four months in the United States, only about 57 per cent do so after three years. In other words, a rise in the refugee employment rate is not 
accompanied by an equivalent drop in the poverty rate. Getting a job does not necessarily end poverty. (p. 115)

The need for more education than threshold language training is likewise stated by The Adult Literacy and Basic Skills Unit (1985) who write:

The ability to communicate effectively in English is clearly essential for any individual wishing to participate fully in our society, particularly as English is the major language within the United Kingdom. A world based on mass communication means that adults who are not able to communicate adequately in English--whether by speaking, reading or writing--are at risk of being excluded from taking an active part in life and work in this country. (p. 3)

This statement, although intended for the United Kingdom, could equally apply to the situation in the United States.

Rowekamp (no date) writes "the intent and goals of both teachers and learners seem to demand an education system" (p. 31), rather than language training. In this respect, she argues that short term language training, in an effort to teach those skills necessary for students to find immediate, entry-level employment does not necessarily satisfy the ultimate goals of the students, nor provide them with the ability to adequately participate socially and economically in the United States.

This attitude was evident in the Minnesota State Department of Education Report on the Evaluation of Adult Refugee ESL Programs (Nelson \& Bringewatt, 1986), which reported that the teachers did not view their educational role as part of the "employment service continuum." They continued, "most agencies have attempted to continue teaching literacy even though the federal directives for employment focus seem to make reading and writing secondary" (p. 34).

The National Literacy Act of 1991 defines literacy as:

an individual's ability to read, write, and speak in English, and compute and solve problems at levels of proficiency necessary to function on the job and in society to achieve one's goals, and develop one's knowledge and potential. (p. 1) 
This definition is significant on three counts. First, it indicates that literacy is to be measured in terms of English language ability, contrary to the fact that English is not formally recognized on the federal level of government as the official language of the United States (Tollefson, 1991).

Second, it defines literacy as the ability not only to achieve professional goals, but also to attain personal goals as well. This definition recognizes the necessity of English literacy within the United States in order to be able to fully participate in society. Thus we see within the United States an inconsistent situation in which it is recognized by the Federal Government that English is fundamental to functioning on an economic and social level within the United States, yet there has been a push to provide only minimal English education to non-native speakers, in order to make them rapidly employable. McKay and Weinstein-Shr (1993) describe the situation as follows:

there is enormous pressure on program administrators to place participants in any job. This emphasis sabotages participants' hopes of developing language and literacy skills for better jobs that would enable them to support their families. Such programs also dramatically illustrate the inconsistency that exists between U.S. national policies which support an expanding role of English literacy and nationally sponsored programs that minimize literacy training. (p. 409)

Finally, within this definition, literacy education must incorporate objectives consistent with the specific needs of the individual learner. These needs can range from survival competency language training to full literacy education. It is the learner who must decide what constitutes the "ability to achieve one's goals, and develop one's knowledge and potential." Learner assessment becomes of primary importance. Only by understanding the learner's needs and abilities can the student be given the instruction necessary to achieve his/her goals. Individualized instruction in the form of one-on-one, and small group tutoring is ideally suited to being able to determine the 
purpose of, and deliver the services required by the ESL adult learner. The challenge is to train and support a staff able to achieve this task.

\section{Classifying literacy practices}

Increasingly, qualitative approaches to the study of literacy have indicated that literacy is a multi-dimensional concept which varies by its social context, reflecting socio-cultural norms of behavior, rather than being a function of individual achievement. Researchers and educators now view literacy in relation to the uses and functions of literacy throughout one's daily life. That is, literacy is now associated with factors such as the purpose for and context in which the literacy is used (see, for example, Graff, 1979; Heath, 1983; Street, 1984). Wrigley (1993) states that

many educators are starting to recognize that perspectives on literacy and illiteracy are shaped by economic, social, political, and cultural dimensions. As a result, literacy is no longer defined as a single construct but rather as a plurality of literacies which are shaped by various social contexts and defined individually as well as collectively. (p. 451)

She presents the concept of a literacy continuum containing several dimensions. These include functional literacy, described as literacy used to function in everyday situations; socio-cultural literacy, which is that literacy which encompasses the knowledge of how literacy practices are different in various groups and the ability to use this knowledge in appropriate contexts; expressive literacy, which is the ability to use literacy to express oneself and reflect on one's personal feelings; and finally critical literacy, which involves the ability to critically analyze and comment on the circumstances of one's own life and the surrounding environment. In this model, as the student increases his/her English abilities, he/she may move along the continuum in order to fulfill the needs or functions associated with the different types of literacy (Wrigley, 1993). 
Given this model of literacy, Wrigley (1993) has created a taxonomy of philosophical underpinnings of ESL literacy curricula. She professes that there are six basic philosophies to literacy education: common educational core, social and economic adaptation, development of cognitive and academic skills, personal relevance, social change, and technological management of education. These philosophical underpinnings are discussed below respectively.

Common Educational Core. A common educational core orientation to ESL literacy education is based on the notion that all students must be provided with a common set of educational experiences. These include a command of the English language, basic literacy skills, and the understanding of the values attributed to mainstream society, or what is often termed "cultural literacy". Basic to this orientation is the effort to prepare students to succeed in the existing educational systems, for example to pass the GED test, or to be prepared to enter into vocational or academic programs.

Social and Economic Adaptation. The social and economic adaptation orientation views the function of ESL literacy education as supplying the students with skills necessary to meet their critical economic needs, the needs of the community, and the needs of society as a whole. This orientation considers improved job performance and the competencies necessary for employability paramount to the educational process.

Developing Cognitive and Academic Skills. The orientation of developing cognitive and academic skills, has the goal of teaching the students how to learn. Within this orientation, it is the process of learning which is stressed. Learning strategies are emphasized, and understanding, more than memorization is the focus of the educational experience.

Personal Relevance. Personal growth and self-actualization are the goals of the personal relevance orientation to ESL literacy. This orientation stresses the school's 
responsibility to make the curriculum relevant and meaningful to the learner, in order to promote meaning and expression in a controlled environment.

Social Change. The social change orientation views the cause of illiteracy as one of inequitable social conditions. Illiteracy is not the cause of poverty, but often the result of poverty. Therefore, the social change orientation addresses issues of power and control, promoting education for liberation. Programs following this philosophy often emphasize students sharing in the control of both the classroom and the program itself.

Technological Management of Education. Developed during the social efficiency movement of the 1970's the technological management of education orientation professes to be value-free and adaptable to any teaching situation be it workplace literacy, academic literacy, or daily life literacy. Education is viewed as a streamlined curriculum package to be administered. This orientation stresses the use of diagnostic testing, training modules, pre and post tests, and overall educational efficiency.

It is stressed that these six orientations by no means are mutually exclusive. Wrigley and Guth (1992) found that it was most common to operate under a combination of orientations. It was also noted that the choice of orientations was most often dictated by the method by which the program was funded, and also by the personal philosophies of the teachers. This was said to cause instances in which the overall orientation of the program was in conflict with the orientation of the teachers providing the ESL literacy education. Although not rigid, this taxonomy is useful in defining and determining general orientations in which to better understand an adult ESL literacy program. 


\section{Instructional Approaches}

Given the varying ESL literacy philosophical orientations, there are many different instructional approaches which can be used to achieve literacy education. Outlined below are common teaching approaches to ESL adult literacy, adapted from The Adult Literacy \& Basic Skills Unit's ESL/Literacy: An Introduction Handbook for Tutors (1985, Chap.2). It must be noted that any given approach is not intended to be used exclusively, but should be called upon and combined based on the students' specific needs and the guiding philosophical orientation(s) of the program.

The Whole Word Approach. The objective of the Whole Word Approach is to allow a meaningful decoding of the entire word or phrase instead of by individual letters. This approach is recommended at the very early stages of literacy instruction especially for learning common words such as street signs and personal vocabulary. The method of demonstration involves reading the word(s) and recognizing the word from within a list, pictures, etc. Words can also be traced or copied onto cards and then used for games.

Literacy Through Language Practice. The intent of this approach is to incorporate literacy skills into the oral skill presentation. This can be done, for example, by having the students produce written scripts for role play, or writing comments after a role play session. This is also an opportunity to present an analysis of the differences between written and oral communication.

The Language Experience Approach. In the Language Experience Approach, students' words, either written or oral, are transcribed and used as the learning text. This approach has the advantage of giving status to the student's own language product, and also one can work with and build upon the students' existing knowledge.

Phonics. It is recommended that this approach be used for ESL learners with no literacy skills in their first language. The purpose of this approach is to 
systematically assign and teach the sounds associated with each letter of the alphabet. Awareness of each sound and how the sounds are blended together is a necessary area of instruction.

Using Context. In order to build skills in the areas of comprehension and prediction, this approach focuses on teaching the importance of understanding the format of text in order to increase comprehension and build scanning skills. This can be done in a variety of ways including using cloze passages, creating scanning activities, or familiarizing the student with the layout of newspapers.

Spelling. The ability to spell does not naturally occur during literacy education and must be specifically taught. There are many techniques to help a learner including the use of auditory presentations of exaggerated speech (knock, knee), kinesthetic approaches such as tracing over words, or visual techniques using flashcards, word jigsaws, or word completion exercises.

\section{PROGRAM RECOMMENDATIONS FROM RESEARCH FINDINGS}

Guth and Wrigley (1992) conducted a 2-year study on adult ESL programs and practices in order to identify and characterize the practices of model adult ESL literacy programs. This study, commissioned by the U.S. Department of Education, determined that

good adult education programs possess the following eight components: community outreach, needs assessment of the learner community, program design, curriculum, approaches and methods, initial assessment and progress evaluation, staff development, and support services. Yet no adult ESL literacy program that participated in this study, even the most successful, was uniformly excellent on all eight program components. (p. 62)

It was noted that quality programs showed strength in a majority of the above designated areas, but that it was believed to be unrealistic to expect a program to excel 
in all areas, given the current resources available to ESL literacy programs. More importantly, these components were considered useful as an organizing reference for programs to self-evaluate their effectiveness.

Also noted in the study were common elements which appeared among successful program models. These were: "learner-centeredness, context-specific teaching, meaning-based approaches, knowledge of the learner community, and a supportive environment for adult learning" (Guth \& Wrigley, 1992, p. 70).

In 1985, the Minnesota Department of Education's Office of Community and Adult Basic Education commissioned an evaluation of the 18 adult refugee ESL programs funded through the Minnesota Refugee Program Office (Nelson \& Bringewatt, 1986). One of the purposes of the research was to identify effective practices in order to aid in future decisions making and planning. This was done by a series of interviews with and observations of coordinators, teachers, and students. The overall program recommendations derived from the study are summarized below in order of importance as perceived by those interviewed.

Hire and support excellent teachers.

Recruit program coordinators with leadership skills, and strengthen the coordinator's role.

Promote coordination with other agencies.

Structure programs that can adjust to students' individual educational needs.

Maximize instructional time and pace.

Also included in the report were recommendations for instructional strategies and classroom methods for all program proficiency levels. These consisted of the following:

Teach students to learn 
Use relevant issues as tools for teaching (i.e. use real situations in the students' everyday lives)

Use flexible responses to immediate issues (i.e. respond to immediate circumstances or issues in students' lives, in this case, the teacher assumes a problem-solving role)

Promote, encourage and enhance learning outside the classroom.

Involve students in educational goals.

Balance the use of appropriate materials.

In addition, specific recommendations were given based on the proficiency level of the student. Included was the recommendation to gradually move from a more teacher-centered approach at the earliest stages of education to a student-centered approach at the higher levels. The student-centered approach was noted to be achieved often by allowing students to actively participate in decisions involved in the activities and management of the classroom. In this manner, teachers were recommended to move to a role of facilitator, structuring classes in order to increase the amount of individual attention given to each student as they worked on activities and projects. It was also recommended to provide more controlied practice in the earliest stages of education, and work towards increasing amounts of free practice as the students progressed. Another recommendation was to increase opportunities for students to use their English abilities as they progressed, by creating situations in which the students were required to be engaged in problem-solving activities in English situations outside of the classroom, utilizing resources that could help create realistic classroom experiences. Finally, it was recommended that in the most advanced stages of education, the teacher should actively coordinate with other local education providers in an effort to prepare and move the students toward their desired goals (Nelson \& Bringewatt, 1986). 


\section{THE ROLE OF VOLUNTEERS}

It was reported for the fiscal year of 1988 that within the Adult Basic Education $(\mathrm{ABE}) / \mathrm{ESL}$ public education system of the state of Oregon, there were 80 full time teachers, and 376 part time teachers. In addition, it was reported that in fiscal year 1989, there were 622 volunteers (Pelavin, 1991). This indicates that over one half of the individuals providing some type of literacy training within the public adult educational system of Oregon for 1988/1989 were doing so on a volunteer basis. Volunteerism is a significant element in literacy education, and causes a unique set of conditions under which an organization operates. Volunteers are motivated by a variety of factors, and often assume their responsibilities with little or no direct experience or training in the field in which they are volunteering.

Miller (1983) states that for nearly every volunteer there is a unique motivation for volunteering. Some of the most widely recognized motivations discussed are listed below:

Learning new skills, developing talents

Meeting people and socializing

Exploring career interests or opportunities

Correcting an injustice to an individual or group

Improving living conditions

Improving the community

Pursuing a personal interest or hobby

Expressing love and concern for others

Filling time in a meaningful way

Change of pace from employment or other full-time pursuits

Remaining active and productive in the community after retirement

Gaining experience leading to a paid job or college degree

Motivational factors are important to understand when developing and maintaining an ESL literacy program staffed predominantly by volunteers. 
Both Byron (1974) and Miller (1983) identify the necessary steps to administer successfully a volunteer program. These include: volunteer recruitment, interviewing, placement, orientation, training, and record maintenance. Each of these steps is best considered as an on-going process. Crandall (1993) reports that "a typical literacy volunteer, working in one-to-one tutoring may receive only $15-20$ hours of preparation during the first year, with even more limited training in subsequent years" (p. 500). This indicates that each contact with the volunteer must fulfill the necessary primary task, and in addition be utilized to its fullest as a training opportunity. Based on Byron and Miller's recommendations, the necessary steps to administer successfully a volunteer program will be discussed below.

\section{$\underline{\text { Recruitment }}$}

Miller (1983) recommends that volunteer recruitment be done throughout the entire year. She stresses the importance of appropriate timing. Also, it is best to plan recruiting efforts directed specifically at a targeted group rather than generally. This can be done by considering specific characteristics of the type of volunteer desired, and then planning recruitment efforts targeted at those individuals.

Interviewing, Placement and Orientation

It is recommended that each applicant have a personal interview with the coordinator. Interviews should be conducted in an informal environment in order to put the applicant at ease. Ample opportunity should be given to the applicant to discuss his or her motivations and abilities, and also to ask any questions. Volunteers not suitable for the given program should be given an alternative plan such as a recommendation to serve in other organizations. Finally, three criteria should be met when evaluating a potential volunteer: interest, ample time to meet the program's needs, and willingness to take part in training and meetings (Miller, 1983). 
Placement and orientation of the volunteer is the next step in initiating a new volunteer. As with recruiting and interviewing, this should be considered a time of training the volunteer (Byron, 1974), as it is the time when the volunteer must know exactly what is expected of him/her, and what to expect from the coordinator. The volunteer must also be made familiar with the facilities and resources available within the organization, emergency procedures, and the overall philosophy of the program.

\section{Training}

Pre-service training of the volunteer is the next stage of initiation to the program. Miller (1983) lists seven areas which a coordinator may wish to include in a pre-service training program for ESL volunteers. They are:

Sensitivity to ESL students/cross-cultural awareness

Pre-literacy, literacy

Repetition and substitution drills

Vocational ESL

Survival ESL

Pronunciation

Resources and materials ( p. 73)

In addition to pre-service training, it is recommended to provide in-service training. This can be in the form of refresher courses to present up-to-date information on new methods, volunteer staff meetings to inform volunteers of new policies or to share new ideas, volunteer newsletters, or interagency workshops and seminars (Byron, 1974).

\section{Record Maintenance}

Due to the fact that many grants and administrative decisions are based on written statistics and results, record keeping is seen as imperative to a successful volunteer organization. It is recommended that each volunteer maintain a time sheet to record the number of hours volunteered. This information is not only important for gathering statistics, but also for reasons of insurance and liability (Miller, 1983). 
Both Miller and Byron emphasize that these steps, recruiting, interviewing, placement, orientation, training, and record keeping, are necessary in order to establish and maintain a successful volunteer program.

\section{ADULT ESL LITERACY STUDENTS}

Guth and Wrigley (1992) state "the individual goals of adult ESL learners are as diverse as the learners themselves, but students know when they are learning and what they need" (p. 98). The remaining section of this chapter discusses general characteristics of adult ESL literacy learners, individual motivations for learning, and program recommendations made by the ESL students themselves.

In a national study done on adult ESL literacy programs (Guth \& Wrigley, 1992), it was reported that generally, ESL literacy learners:

have not yet learned to read and write in English although they may have some proficiency in spoken English and may have developed excellent functional "survival skills."

tend to have had few years of formal schooling and may be reluctant to enter or re-enter conventional schools.

have had limited opportunities to acquire literacy in their native countries and they may not be literate in their native languages. Some learners may have strong coping skills and a social network that allows them to function quite well without much knowledge of print. (p. 7)

This is consistent with Klassen and Burnaby's (1993) report on the adult ESL literacy population of Canada, in which they discuss the specific strategies utilized by those non-literate adults. It was found that the adults interviewed had little formal education in their originating country, and were typically illiterate in both their L1 and English. Regardless, they were found to manage and participate reasonably effectively in most facets of their daily lives. This was done by extensive networking with friends, 
relatives, and business and government officials. ESL classes were often seen to be a vehicle for networking and making the contacts necessary to function in daily concerns.

Adult ESL literacy learners study English for a variety of reasons. In addition to providing an opportunity for networking as mentioned above, Guth and Wrigley (1992) list seven stated reasons why the students they interviewed wished to learn to study English. These are summarized below.

Self-defense. Many students wish to learn English in order to articulate errors made on the part of sales clerks, government officials, etc.

Something owed to oneself. Often, learners view learning English as a time when they can finally do something for themselves after educating their own children.

Independence. So as to not have to rely on others for translating and daily tasks, students wished to learn English to perform these tasks themselves.

Communicate with family. Many grandparent age learners study in order to communicate with their grandchildren who speak only English.

Better jobs. Reading and writing were felt to be necessary by many to get a better job.

Find jobs. Other learners felt that they needed literacy education in order to seek work.

Improve skill. Workers often conveyed the fact that they needed literacy training in order to improve their skills for their current jobs.

As a portion of the study done of adult ESL refugee programs funded by the Minnesota Department of Education (Nelson \& Bringewatt, 1986), five groups of students from various programs met with the researchers for informal interviews to express their perspective on the educational programs. Some of the overall observations from these interviews are listed below: 
Students were generally unclear about how long it would take to learn English.

Answers to "why are you learning" covered a wide range. Some students wanted to be able to talk to American friends, to learn to drive or shop or to keep up with their children as they learned English.

Finding employment was mentioned more frequently than other motivations but it was not necessarily the central reason for taking classes.

Some students noted that their goal was to attain a job that had future potential, so they were frustrated about the minimum training offered through ESL. (p. 29-30)

In addition to these observations, students' comments and perceptions in regard to their classes were noted as follows:

Almost all agreed to the importance of practicing speaking English outside the class but almost no one spoke English at home or in any other setting in which they were not forced to use English.

Their common message was that they want to learn faster and want to pick up the pace of the classes. Their specific recommendations were:

Don't waste time on class schedule.

Start on time. Do not tolerate late comers. Minimize break times.

Maximize use of class time.

Don't address remedial problems at the expense of others.

Maintain efficient class size.

Ranges were generally 8 to 12 students per teacher.

Students want more of everything; vocabulary, pronunciation, reading, writing, conversation.

They would prefer to work through a book and finish it instead of skipping from chapter to chapter.

They wanted to learn faster but also responded that they would be unable to study at home more, had few chances to practice and had little time to do more than they are doing now outside their family and work obligations. (pp. 30-31) 
In the nation-wide study conducted by Guth and Wrigley (1992), students also articulated what they preferred and felt necessary for their learning. Advanced students felt that in order for them to make progress, it was necessary to have the same teacher, instead of a different volunteer each class day. The advanced students also wanted more grammar at the higher level classes, and requested dictation and math.

It was also found that, commonly, adult learners must overcome personal obstacles to attend classes. These include: the severe anxiety evoked by attending school for the first time in one's life; being rejected by educational programs due to not possessing literacy skills; and coping with the logistics of attendance in relation to transportation, child care, and classes compatible with work schedules (Guth \& Wrigley, 1992).

\section{SUMMARY}

This chapter has discussed the history of adult literacy in the United States, noting that as the nation became more industrialized, literacy needs became more apparent. The historic events of the United States helped to promote the diversity of organizations providing adult ESL literacy education that are seen today.

Despite the push toward short term language training promoted by many federally funded programs, many educators and learners prefer to work towards a goal of English language literacy viewed from a socio-cultural perspective of literacy; that is, the type of literacy necessary to the given context. Literacy therefore is defined as the language ability necessary to achieve both professional and personal goals. This multidimensional perspective of literacy is accompanied by various philosophical underpinnings of literacy curricula, and also by various teaching approaches. Ultimately the choice of the approach or training method employed should be determined by the needs of the adult ESL learner. 
Volunteerism is a significant element to literacy education, and causes a unique set of conditions under which an organization operates. Volunteers are motivated by a variety of factors, and often assume their responsibilities with little or no direct experience or training in the field in which they are volunteering. For this reason, it becomes important to provide a framework in which to allow the volunteer to succeed. This can be done by effectively recruiting, interviewing, placing, orienting, and training volunteers, in addition to maintaining accurate records.

Based on research findings of adult ESL literacy programs throughout the nation, it has been recommended that classes should be learner-centered, contextspecific, and meaning-based, housed within a supportive environment for adult learning. Educators should be aware of the varied learner goals of ESL students, and work with the knowledge of the challenges faced by many of their students, in addition to the unique abilities they possess. 


\section{CHAPTER III}

\section{RESEARCH METHOD}

The research method chosen for this study was a descriptive case study. This method was chosen as it was the objective of the study to provide an overall description of the activity provided by one particular type of deliverer of ESL services. A variety of means of gathering data were employed to produce a more powerful description. Therefore, data gathering techniques included the use of a data base information system of non-profit organizations, telephone interviews, and classroom observations.

There were three parts to this study: identifying the organizations, interviewing the ESL program coordinators of each organization, and classroom observation and/or teacher interviews within a stratified sample of the ESL organizations. Each of these parts is discussed below respectively.

\section{IDENTIFICATION OF THE ORGANIZATIONS}

In order to answer Research Question 1, an attempt was made to identify all non-profit organizations providing adult ESL literacy services in Multnomah County, Oregon. This sample, non-profit organizations, was chosen, as through personal experience, and by speaking with other members of the ESL educational community, it was noted that the non-profit sector was known to be largely diverse, and often not formally linked to the ESL service distribution network provided by the community college system. It was believed that by investigating these organizations, it would be possible to establish a link with the support services provided, and also among the organizations themselves. 
An exploratory approach was employed to identify the existing programs. This was initiated by working with two preliminary sources of information. A list of contact persons was given to the researcher by the Volunteer Coordinator at Portland Community College (PCC), indicating which contacts would be most pertinent to the study. Second, the data base information of non-profit organizations at the Multnomah Public Library was reviewed, narrowing the search by requesting information relating only to Multnomah County, Refugees, . and Ethnic groups. From the two initial sources, a call list of thirty-eight organizations was created.

In addition to these sources, a question was included on the questionnaire to be administered to the coordinators of each identified organization, with the specific purpose of obtaining additional information on other programs known by the coordinators. This portion of data gathering was an on-going process. The system of identification was chosen due to the fact that preliminary research indicated that there was not one single source for this information. This lack of information was one of the initial inspirations for the study.

\section{PROGRAM COORDINATOR TELEPHONE INTERVIEWS}

From the call list created from the first portion of research, telephone calls were made to each of the organizations. The researcher identified herself to the receptionist of the organization and asked if their organization provided ESL services. If the response was "nd", the researcher inquired as to where their clients who needed these services were referred. This information was recorded, and all new organizations which qualified for the study were added to the call list.

Structured telephone interviews were performed with the ESL program coordinators of each organization that offered services. If there was not a program coordinator within the organization, the interview was performed with a lead teacher. 
The elicitation technique of telephone interviews was chosen in lieu of a written survey in order to increase the response rate. It was estimated that there would be from 10 to 15 organizations to interview; therefore, telephone interviews were selected instead of personal interviews due to time restrictions. A total of 14 interviews took place, and each interview lasted from 20 to 40 minutes, depending on the interest and speaking style of the interviewee.

The telephone interviews each followed a prescribed format. An introduction was given explaining the nature and purpose of the study. Responses to the questionnaire were recorded in the form of verbatim notes, and probing or rephrasing of the question was often necessary to generate pertinent information. The questionnaire essentially consisted of three parts, discussed below. It was reviewed by Marie Hermanson of the Portland Community College (PCC) Volunteer Tutor Program, and piloted on two organizations.

\section{Mailing List Information}

This section's primary function was to generate basic information to create a mailing list in the hopes of establishing a more formal network within this sector of ESL instruction providers, and also to link this sector with existing resource providers such as PCC, and The Portland Literacy Council. Part of the aim of this study was to strengthen communication channels between the existing agencies, and reduce isolation in order to produce a more coordinated effort. The interviewees were given the option of having this information included in a mailing list. Information generated from this section included the name, address and telephone number of the organization, with a brief description of the services provided by the organization. 
Nature and Characteristics of the Program.

The information generated from this section remains confidential in relation to the organization which has provided the data. This portion of the interview attempted to identify specific program characteristics including the following:

Who are the teachers and how are they recruited, trained and tracked?

Who are the students and how are they recruited, assessed and tracked?

What types of programs are being offered, and what types of materials are being used? This included information such as types of instructional formats offered (i.e. one-on-one tutoring sessions, small group instruction, or classroom instruction), a specific teaching approach promoted by the organization, and instructional text books used and/or provided by the organization.

Also included in this section were a series of questions to determine if the coordinator believed his/her methods in the specific areas were well suited to the objectives of the program. The purpose of these questions was to customize the information to the specific program. It was believed that perhaps those characteristics and procedures thought necessary within a given program were a product of the researcher's preconceived beliefs. Yet these elements may not have been perceived to be particularly important to those involved in a given organization. This was an attempt to understand more fully what was felt to be necessary by the coordinator to maintain a good adult ESL program. Below are listed the questions used to elicit the rated effectiveness of a given program's practices to program objectives.

Please indicate whether you 1 strongly agree, 2 agree, 3 are neutral, 4 disagree, or 5 strongly disagree with the following statements:

Our current methods of student recruitment well suit our program objectives.

Our student assessment techniques well suit our program objectives. 
Our methods of tracking students' educational progress well suit our program objectives.

Our current methods of recruiting volunteers well suit our program objectives.

The teacher/tutor training practices we employ well suit our program objectives

Our current method of tracking volunteers well suits our program objectives.

\section{$\underline{\text { Support Service Needs Evaluation }}$}

This section was created to determine what resources were felt to be most necessary and most valuable to the organization. Included was information on staff development, funding information, and material resources.

Data from Part One of the interview, providing permission from the coordinator was granted, were recorded alphabetically into a contact information packet and given to the coordinator of the PCC Volunteer Tutor Program.

Data from Parts Two and Three, upon termination of the telephone interview, were assigned a letter in order to produce anonymity, and the data were transferred verbatim into a data base skeleton questionnaire maintained on a computer. When the interviewing was completed, responses to each question were analyzed.

It was noted after reviewing the organizations that there were two basic types of ESL service providers who participated in the study. The first group, labeled Group I, was identified as those organizations which perform a variety of social services related to the needs of their clients; ESL services are included as one of those services. The coordinators working for Group I are paid employees of the social service organization, and coordinating the ESL program is one of the many tasks performed by the coordinator. A typical example of this type of organization would be a Volunteer Agency (Volag), whose primary function is refugee resettlement. Under this heading, 
English language education services are provided in addition to employment counseling, housing assistance and other services necessary to aid the resettlement process. A coordinator in this type of organization may, in addition to coordinating the ESL services, be involved in refugee sponsor development or case management.

The other group, Group II, consists of volunteer coordinators who are predominately teachers within the program, and who in addition have the responsibility of coordinating the program. This group of programs was noted to be less formally linked to the organization under which they served. A typical situation from this group would be a language program through a church organization. Unlike Group I, the coordinators of this group conduct the coordination from their home. Their main function is that of teaching and/or tutoring, but they also are responsible for the overall coordination of the program.

It was necessary to study the two groups independently, as well as collectively, as although both groups share many commonalties, within certain areas, each group possesses unique characteristics affecting program management and support services needed. It was noted that Group I and Group II rated the value of support services offered in a very different manner, indicating that these two groups have differing interests.

In addition, Group II, due to the fact that coordinators characteristically work independently from the organization under which they serve, represents a sector of ESL service providers less connected to the current ESL delivery system established through federal funding. This situation decreases the likelihood of communication with and knowledge of other ESL service providers. Group II organizations are potentially less aware of the availability of the support services provided by the current ESL delivery system established by the government, and in turn, it is more difficult to identify and facilitate this type of program due to the relative isolation. These differences between 
the two groups must be considered when characterizing the non-profit sector of ESL service providers.

Upon completion of dividing the organizations into the two groups, organizations were then re-coded using letters A-G for Group I, and T-Z for Group II. This distinction of letters was used to facilitate discussion of the organizations while allowing them to remain anonymous.

\section{TEACHER/TUTOR INTERVIEWS AND INSTRUCTIONAL OBSERVATION}

Based on the groups derived from the data analysis of the coordinator interviews, a sample was chosen from which to perform individual interviews and/or instructional observations. For each group, two organizations were chosen. Although data from the study indicated that the majority of ESL services were conducted on a one on one basis, research emphasis in this portion of the study was placed upon classroom teaching situation. This was done for two reasons. First, it was believed that in order to provide data worthy of generalization, the study of one on one situations required a sample size much larger than was the scope of this study. In addition, preliminary research indicated that the current system of ESL delivery within adult literacy education has been primarily directed at one on one tutoring situations, yet it was found that many programs in this study did conduct classes which were taught by volunteers. It was believed that it would be more beneficial to the needs of the community to study classroom practices, in order to better understand this type of service.

Programs were chosen based on location and targeted student populations. In addition, organizations were reviewed by their responses to the questions concerning their specific program practices in relation to the organizational goals. Two organizations were chosen that rated themselves favorably, and two that did not rate 
themselves as favorably. Ethnographic techniques were employed for this portion of the study, in order to produce descriptive data for the given categories. It was believed that this approach coupled with coordinator interviews had the potential to produce a more reliable description of the nature and characteristics of each ESL program.

Observation and teacher interviews were guided by the general objective of determining the nature of a program on the instructional level. No specific questions were prepared for this portion of the study. Instead, the researcher attended a session, and wrote continuous notes throughout the lesson. Teacher background information was gathered strictly by that information volunteered by the teacher with a minimum of prompts such as "How did you get interested in teaching?", "Where did you receive your training?", or "what books are you using...do you like them?" for example. Four observation/interviews were scheduled and each took approximately two to three hours to perform. The notes taken during the interview/observation process were transformed into descriptive narratives.

\section{LIMITATIONS OF THE RESEARCH METHOD}

One of the major limitations of this study was the inability to validate that the study included all of the eligible organizations in Multnomah County, Oregon. Lack of funding, volunteer staffing, and the tenuous nature of the student clientele's life all contribute to the volatile nature of these ESL service providers. The data generated by this method of research are sensitive to the elements of change that predominate within this sector of ESL providers. It is believed that given this limitation, enough data have been generated from the techniques employed to present an overall accurate picture of the organizations discovered, but this is not to state that in spite of exhausting all listed resources, all organizations have been identified. 
In addition, the interview technique presented a potential threat to internal validity on two main counts. First, the data were potentially subject to the bias of the researcher when conducting the interview. It was imperative that the probing and answer clarification process be as objective as possible.

Second, the accuracy of the gathered information was dependent upon the objectivity of the person being interviewed. In addition, the coordinators interviewed from Group I were found to often maintain only minimal contact with the volunteer teachers/tutors. This situation could have produced mis-information on the specifics of classroom activities performed by the teacher/tutor.

\section{SUMMARY}

The purpose of this study was to identify and produce a description of the adult ESL literacy programs offered by non-profit organizations within Multnomah County, Oregon. It was believed that by employing several methods of data gathering including the use of a public access data base, telephone interviews with program coordinators, and classroom observations, an overall picture of this sector of ESL service providers could be obtained. This study was not a prescriptive evaluation, but a description of an existing situation at a particular point in time; methods therefore were chosen to best achieve this. Given the limitations of this study, it is believed that this was the best design to achieve the objective of this research. 


\section{CHAPTER IV}

\section{RESEARCH FINDINGS}

As noted in Chapter 3, this study consisted of three parts. The following is a description of those findings generated by the techniques discussed in Chapter 3. The findings have been presented according to the stage in which they were elicited.

\section{IDENTIFICATION OF THE ORGANIZATIONS}

Due to the fact that there was no single source from which to identify qualifying organizations, a call list of 38 organizations was produced as described in Chapter 3. Of these $38,18 \%$ or 7 of the listed phone numbers were either disconnected or incorrect numbers. Two, or $1 \%$ of the organizations were never interviewed, as successive attempts to contact the organization failed due to lack of responses to messages left on answering machines. The remaining 29 organizations, $76 \%$ of the original 38 , were contacted. Of this $76 \%, 10$ organizations, or $26 \%$ of the original 38 , qualified and coordinator telephone interviews were performed. Nineteen of the organizations, $50 \%$ of the original 38 , did not qualify as they did not provide nonvocational ESL services to adults within Multnomah County, Oregon. Only a short inquiry interview was conducted with these nineteen organizations. From this process, 13 new leads were generated from which a second phase of calls proceeded.

The second phase of calls yielded no bad numbers. There were, however, 4 unsuccessful attempts, $31 \%$ of the original 13. This again was due to a lack of response to messages left on answering machines. The remaining 9 organizations, $69 \%$ of the original 13 , yielded 4 , or $31 \%$, qualifying organizations for which coordinator 
telephone interviews were performed. Five of the organizations, $38 \%$ of the original 13, did not qualify and only a short inquiry interview was performed. From this process, no qualifying leads were generated.

In sum, attempts were made to contact 51 organizations. Of these 51,13 organizations (25\%) were never contacted, $7(13 \%)$ due to bad telephone numbers, and $6(12 \%)$ due to unsuccessful attempts. The remaining 38 organizations (75\%) were contacted and $14(27 \%)$ of the organizations qualified for the study. Telephone interviews with the coordinator were conducted with these 14 organizations. From this exploratory process, 13 new organizations were discovered from which to contact. Table 1 summarizes the results for this portion of the study.

TABLE I

RESULTS FROM CALLS MADE TO IDENTIFY ORGANIZATIONS

\begin{tabular}{|l|r|r|r|r|r|r|}
\hline & PHASE I & $\begin{array}{c}\text { \% OF } \\
\text { ORIG 38 }\end{array}$ & $\begin{array}{c}\text { PHASE } \\
\text { II }\end{array}$ & $\begin{array}{c}\text { \% OF } \\
\text { ORIG 13 }\end{array}$ & TOTAL & $\begin{array}{c}\text { \% OF } \\
\text { ORIG 51 }\end{array}$ \\
\hline BAD NUMBER & 7 & 18.4 & 0 & 0.0 & 7 & 13.7 \\
\hline UNSUCCESS ATMPT & 2 & 5.3 & 4 & 30.8 & 6 & 11.8 \\
\hline FULL INTERVIEW & 10 & 26.3 & 4 & 30.8 & 14 & 27.4 \\
\hline SHORT INTERVIEW & 19 & 50.0 & 5 & 38.4 & 24 & 47.1 \\
\hline TOTAL & 38 & 100.0 & 13 & 100.0 & 51 & 100.0 \\
\hline NEW LEADS & 13 & & 0 & & 13 & \\
\hline
\end{tabular}

PROGRAM COORDINATOR TELEPHONE INTERVIEWS

\section{Mailing List Information}

Of the 14 organizations which qualified and participated in the telephone interviews, 12 organizations wished to be included on a mailing list. These were divided equally between groups classified as Group I and Group II. One organization from Group I declined as they were already closely in contact with PCC and therefore 
believed that they already received adequate information. The other organization, from Group II, declined as they felt that their services were achieving their goals, and that additional networking was not necessary. Nine organizations expressed interest in meeting other ESL service providers, 5 were from Group I and 4 from Group II. Those who declined did so because of time constraints. This list was forwarded to the PCC Volunteer Tutoring Program and to The Portland Literacy Council. Their information will be updated accordingly. Appendix A contains the mailing list generated from this portion of the research.

Nature and Characteristics of the Programs

As noted above, 14 organizations were identified, qualified, and agreed to participate in this study. For ease of discussion, the results from the interview have been presented for each of the two groups, Group I and Group II, and then summarized as a whole.

Briefly, as explained in detail in Chapter 3, the organizations in Group I (those organizations labeled A through $\mathrm{G}$ ) are characterized as organizations providing multiple social services to their clients, with ESL included as one of these services. The coordinator is a paid employee of the organization, although he/she has many other responsibilities in addition to that of ESL program coordinator. Usually, the coordinators of Group I are not involved in teaching or tutoring, although may substitute on occasion.

The organizations in Group II (those organizations labeled $\mathrm{T}$ through $\mathrm{Z}$ ) are characterized as ESL service providers relatively independent of the organization under which they are headed. The coordinator is a volunteer, working out of his/her home and in addition to teaching and/or tutoring has the responsibility of overseeing the program. Results from this portion of the interview are presented as follows: general program characteristics, student information, and teacher/tutor information. 
Number of Years in Operation. Within Group I, it was seen that the majority of the organizations had been offering ESL services for more than 3 years. Two organizations had been doing so for between 1 and 2 years. Three organizations had been providing services for 3 to 5 years. One organization had been providing services for between 5 and 6 years, and one for 10 years.

Within Group II, it was found that the majority of the programs had been in existence for less than 3 years. One program had been offering services for only $21 / 2$ months at the time of the interview, and three more reported services beginning less than 3 years ago. Two organizations reported having been in existence from 3 to 6 years, and one organization was established 19 years ago.

Overall, combining Group I and Group II, the majority of organizations had been providing services for 3 years or more. Figure 1 depicts the findings of the length of existence for each organization.

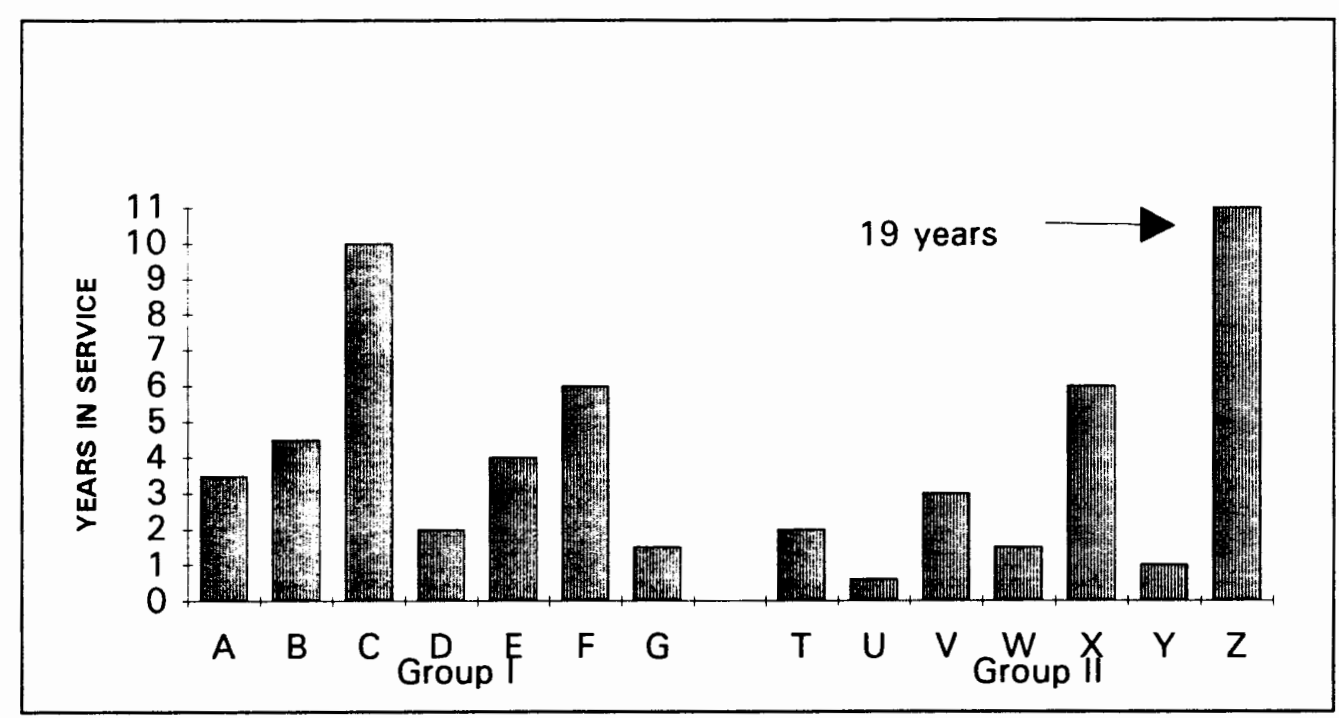

Figure 1. Length of ESL service in years

Types of Services Offered. It was reported that there were four types of services offered: one on one tutoring, small groups, classes, and a video tape program. 
Within Group I, the most common type of service provided was one on one tutoring. Five organizations offered one on one tutoring, four offered small group instruction, three held classes, and one organization provided a video tape instructional program.

Overall, one on one tutoring was most common, followed closely by classroom instruction. Table 2 summarizes these findings.

TABLE II

TYPES OF SERVICES OFFERED

\begin{tabular}{|l|c|c|c|}
\hline \multicolumn{1}{|c|}{ SERVICE } & GROUP I & GROUP II & TOTAL \\
\hline CLASSES & 3 & 4 & 7 \\
\hline SMALL GROUPS & 4 & 1 & 5 \\
\hline VIDEO & 1 & 0 & 1 \\
\hline ONE ON ONE & 5 & 3 & 8 \\
\hline
\end{tabular}

Group I: $n=7$, Group II: $n=7$

Location of Instruction. The location of instruction varied by the type of service provided, and the needs of the students. One on one tutoring and small group instruction were normally conducted in the student's home. Classes were held on the premises of the organization which provided the service with the exception of one organization which provided classes in the community room of a large apartment complex.

Instructional Materials Used. It was found that each organization used a large variety of materials. These were usually supplied by the organization or the volunteer, although approximately one fourth of the organizations reported that students paid for at least some of the books used, particularly their text and workbooks.

The most popular published materials used were The New Oxford Picture Dictionary (Parnwell, 1978) with accompanying workbooks, and Side by Side (Molinsky \& Bliss, 1989). In addition to these texts, volunteers made use of various 
other published materials specific to ESL instruction including the Challenger graded series distributed by Oregon Literacy. It was also reported that volunteers used many published materials produced by PCC or through the main office of their organization, and a large number of organizations reported using realia such as newspapers, pictures, employment forms and other forms. A few organizations reported initially trying to use children's books, but found the materials to be overall unpopular.

Number of Students Served. It must be noted that estimations of student enrollment were often voiced as difficult to state. Students were reported to often attend on a sporadic basis, or attend for a given period of time, leave, and then return. In the case of ESL classes, the coordinators and lead teachers appeared to have no formal system of tracking students; therefore, an exact count was not possible. The information presented below is an estimation given by the coordinator or lead teacher of each program. In all cases, the high figure has been presented when the information was reported as a range; i.e. 10-12 was reported as 12 .

It was reported by those coordinators of Group I, that an approximate total of 325 students were being served at the time of the interviews. The number of students served by each organization ranged from 12 students served by one organization to 100. The most common number of students served by one organization from Group I was approximately 40 students, as reported by three organizations.

Group II reported serving approximately 103 students. The number of students served by one organization ranged from 10 to 25 . The most common number served, reported by four organizations, was from 8-12 students.

The sum total of students served by those organizations identified by this study was reported to be approximately 428 . As a point of reference only, it was found that during the school year of 1990-91, within the entire state of Oregon, 14,402 adults were reported to be enrolled in public adult ESL education programs (Olsen, 1994). 
Although it is impossible to corroborate the two numbers, it is possible to note that a significant number of students are being served by these 14 organizations.

Length of Attendance. Estimations on how long a student attends a given program were again reported to be a difficult item to approximate. Interviewees stated that this figure varied greatly depending on the student. Also, due to the policy of open entry/open exit within most classrooms, students may, for example, attend classes regularly for 3 months, leave the area for a period of time, and then several months later return to class. As it was noted that no individual student records were kept by the coordinator or teachers, tracking the length of time spent in a particular ESL program was, at best, a rough estimate. The figures reported here are those stated as an "average" by the coordinator when they were able to do so. On nearly all occasions this average was prefaced by an explanation of the situation explained above and also with a note that many students attend much longer than the average, and many shorter. Given this, Figure 2 depicts the length of attendance by organization.

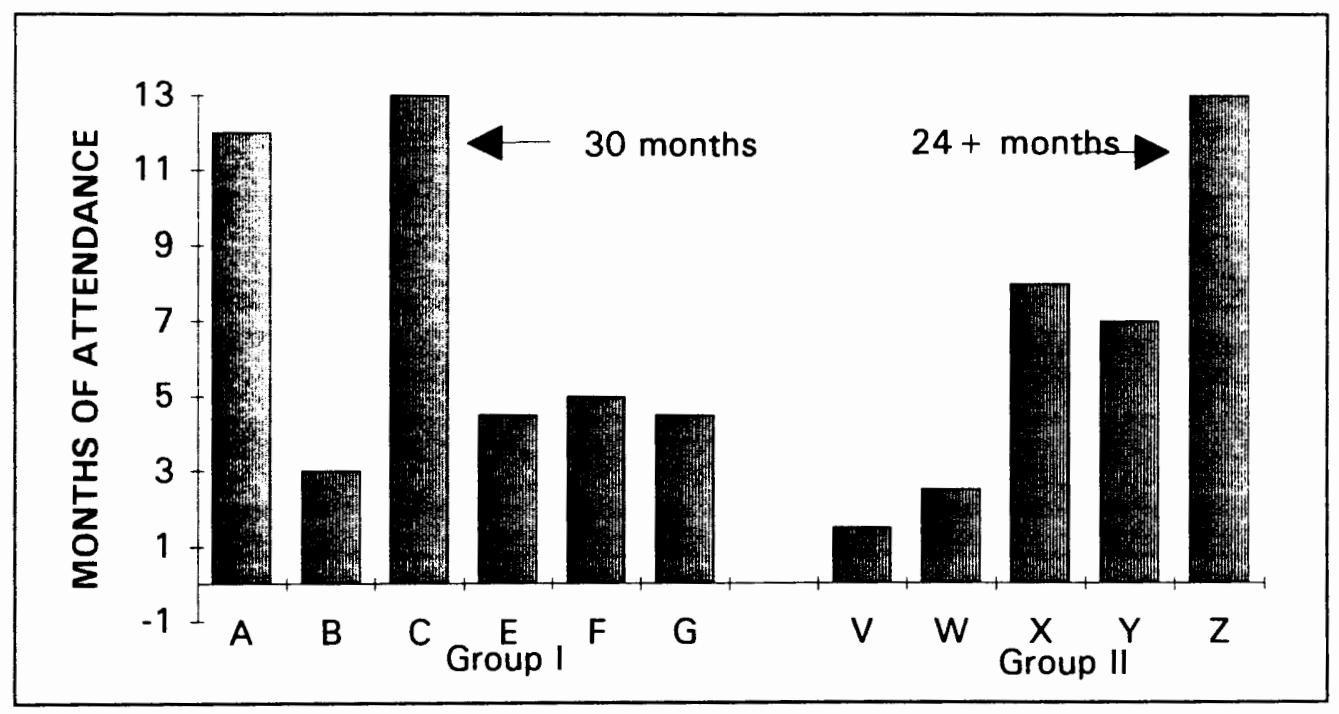

Figure 2. Average length of student attendance in months 
Within Group I it was reported that the most common time that a student spent in a given program was 3 to 6 months. Four of the six organizations that felt they could estimate this figure reported this length of attendance. In addition, one organization reported an average attendance of 9 to 12 months, and one reported average attendance at over 2 years.

Group II reported equally common average attendance lengths of 1 to 3 months, and 6 to 9 months. That is, of the five organizations which stated that they could estimate the length of student attendance, two reported an average length of attendance of 1 to 3 months, and two at 6 to 9 months. One organization reported attendance averages of over 2 years.

Overall results of both groups indicate that the majority of organizations served students who attended an average of less than 9 months.

By analyzing the length of attendance reported by each coordinator in relation to the number of students served by that given organization, it is possible to get a rough estimate of the average length of attendance of the students served in this sector of the ESL service community. Of the 317 students accounted for by the program coordinators who gave estimates of the length of attendance in Group I, it was found that the average attendance length of Group I was a little less than 8 months. Within Group II, this length doubled to slightly over 16 months. The overall total for both groups was found to be slightly over 9 months as the average length of attendance for any given students within this sector. Table 3 depicts the number of students in relation to the average length of attendance reported in months for each organization able to provide this information. 
TABLE III

ATTENDANCE AVERAGES BY GROUPS SHOWN IN MONTHS

\begin{tabular}{|c|r|r|r|}
\hline $\begin{array}{c}\text { ORGANIZA } \\
\text { TION }\end{array}$ & $\begin{array}{c}\text { STUDENT } \\
\text { NUMBER }\end{array}$ & $\begin{array}{c}\text { AVE. } \\
\text { LENGTH } \\
\text { OF STUDY }\end{array}$ & $\begin{array}{c}\text { AVE. } \\
\text { LENGTH } \\
\text { OF STUDY } \\
\text { PER STDT }\end{array}$ \\
\hline A & 12 & 12.0 & \\
\hline B & 65 & 3.0 & \\
\hline C & 40 & 30.0 & \\
\hline E & 100 & 4.5 & \\
\hline F & 60 & 5.0 & \\
\hline G & 40 & 4.5 & \\
\hline GROUP I & & & 7.79 \\
\hline V & 12 & 1.5 & \\
\hline W & 10 & 2.5 & \\
\hline X & 10 & 8.0 & \\
\hline Y & 10 & 7.0 & \\
\hline Z & 25 & 24.0 & \\
\hline GROUP II & & & 16.31 \\
\hline TOTAL & 384 & & 9.28 \\
\hline
\end{tabular}

Populations Served. It was found that an equal number of programs existed which served both a specific ethnic group and a variety of ethnic backgrounds served within one program. Group I most commonly reported serving a mixture of populations within one organization. Five organizations reported this type of situation, and predominantly served refugee populations. Within Group II, serving a specific ethnic group was more common, as reported by five of the organizations.

Specific ethnic groups served by either group, presented here in order from most common to least, were Russian (served by three organizations), Hispanic (served by two organizations), Polish (served by one organization), and Tibetan (served by one organization). Those organizations providing services to students of a mixture of ethnic backgrounds usually did so in a one on one or small group situation. In turn, those serving a single ethnic group often provided this service within a classroom situation. 
Recruitment. It was found that most organizations employed a variety of means for student recruitment, which included word of mouth, social organization referral or refugee assignment, fliers and posters, church announcements, and registration parties. Table 4 depicts the means for student recruitment by Group I, Group II, and a total for both.

TABLE IV

METHODS OF STUDENT RECRUITMENT

\begin{tabular}{|l|c|c|c|}
\hline \multicolumn{1}{|c|}{ METHOD } & GROUP I & GROUP II & TOTAL \\
\hline WORD OF MOUTH & 4 & 3 & 7 \\
\hline REFERRAL/ASSIGNMENT & 4 & 2 & 6 \\
\hline FLIERS/POSTERS & 3 & 2 & 5 \\
\hline CHURCH & 1 & 2 & 3 \\
\hline PARTIES & 1 & 0 & 1 \\
\hline
\end{tabular}

Group I: $n=7$, Group II: $n=7$

It can be seen that the most common means of recruitment by Group I was by word of mouth and by refugee assignment/social service referral. The next most common means was by fliers and posters, and this was followed by church announcements and registration parties.

Within Group II, word of mouth was the most common means of student recruitment, followed by refugee assignment, fliers and posters, and church announcements, which were equally common.

Overall, seven organizations recruited by word of mouth, six by referrals and refugee assignment, five by fliers and posters, three by church announcements, and one organization held a registration party.

When asked to rate the following statement "Our current method of student recruitment well suits our program objectives" on a scale of 1 to 5 , with one strongly agreeing, 2 agreeing, 3 neutral, 4 disagreeing, and 5 strongly disagreeing, the average 
rating for Group I was 1.86. Group II's average response was 2.20. The average rating for both Groups was 2.0, which indicates that overall, the organizations interviewed agreed that their methods of student recruitment well suited their program objectives.

Assessment. Coordinators were asked to rate both their methods of initially assessing their students' English abilities, and also their methods of assessing their students' language goals. The latter question, methods of assessing student language goals, was met with confusion on many occasions, and the researcher recognizes that this was a poorly stated question. Therefore, data from this question were inconclusive. A common response to this question was to discuss the assumptions made due to the student population as to why the students wanted to learn English, not necessarily how they gathered this information.

Organizations identified multiple means of initially assessing their students' language abilities. Those reported were personal interviews by the coordinator, tests administered by teachers or coordinators, informal methods by the teacher, and selfassessment. It was also reported on three occasions that assessment was the responsibility of the teacher/tutor and thus varied by the individual.

Group I showed relatively equal use of each of the means of assessment, although Group II most commonly employed informal means of assessment by the teacher. This informal means was often described as a short initial conversation with the new student, with ability assessment based upon comprehension checks with question and answer techniques, and pronunciation. Overall, informal methods of assessment by the teacher were the most common response to the means by which an organization evaluates its students. This was followed by equal responses of test, and self-assessment. Table 5 depicts the methods of initial student assessment by each group. 
TABLE V

METHODS OF INITIAL STUDENT ASSESSMENT

\begin{tabular}{|l|c|c|c|}
\hline \multicolumn{1}{|c|}{ METHOD } & GROUP I & GROUP II & TOTAL \\
\hline INFORMAL & 1 & 5 & 6 \\
\hline TESTS & 2 & 2 & 4 \\
\hline SELF-ASSESSMENT & 1 & 3 & 4 \\
\hline VOLUNTEER RESPONSIBILITY & 2 & 1 & 3 \\
\hline COORDINATOR INTERVIEW & 2 & 0 & 2 \\
\hline
\end{tabular}

Group 1: $n=7$, Group II: $n=7$

one representing strongly agree, and 5 representing strongly disagree, the average rating for Group I was 2.14. The average rating for Group II was slightly higher as 2.33. The overall score for this area of service provided was rated at 2.30. This score represents a tendency to agree that their practices well-suit their objectives.

Organizations also identified various means of tracking their student's learning progress. These included tests, self evaluation, and weekly student journals. Also reported were responses that no formal method was used, as assessment was done within the context of the class, or that tracking educational progress was the tutor/teacher's responsibility and therefore it was not known by the coordinator.

Of these responses, within Group I, the most common response was that tracking educational progress was the responsibility of the teacher/tutor as reported by three organizations, the next most common means was through test, followed by selfevaluation and no formal means.

In Group II, five of the seven organizations stated no formal means of measuring student progress. Other responses indicated that it was the tutor/teacher's responsibility; one organization stated that they used journals in which the student wrote weekly in order to have a record of their increased abilities. 
Overall, it was reported that within the two Groups, the majority of organizations had no formal means of tracking their students' educational progress. Table 6 depicts the responses to methods of tracking students' educational progress.

TABLE VI

METHODS OF TRACKING STUDENTS' EDUCATIONAL PROGRESS

\begin{tabular}{|l|c|c|c|}
\hline \multicolumn{1}{|c|}{ METHOD } & GROUP I & GROUP II & TOTAL \\
\hline NO FORMAL METHOD & 1 & 5 & 6 \\
\hline VOLUNTEER RESPONSIBILITY & 3 & 1 & 4 \\
\hline TESTS & 2 & 0 & 2 \\
\hline SELF-EVALUATION & 1 & 0 & 1 \\
\hline STUDENT JOURNALS & 0 & 1 & 1 \\
\hline
\end{tabular}

Group I: $n=7$, Group II: $n=7$

When asked to rate their techniques to track students' educational progress on a scale of 1 to 5, the average rating for Group I was 2.64. The average rating for Group II was lower at 2.0. The overall score for this area of service provided was rated at 2.32. This score represents a tendency of slightly below agreement that the methods used suited the program objectives.

Number of Volunteers. Within the Groups interviewed, it was found that all teaching and tutoring were done on a volunteer basis. Table 7 depicts the number of tutors and teachers reported for organizations in Group I and Group II. Within Group I there were reported to be a total of 134 volunteers providing ESL instruction. Of the 134,24 , or $18 \%$ were teachers (defined in Chapter I as instructing groups of more than 6 students) and 110 , or $82 \%$ were tutors (defined in Chapter I as providing one on one or small group instruction). Comparing the total figure of volunteers with the reported 325 students reported attending organizations from Group I, it can be seen that there was a student/volunteer ratio of 2.43:1. 
TABLE VII

NUMBER OF VOLUNTEER TUTORS AND TEACHERS BY GROUP

\begin{tabular}{|l|c|c|c|c|c|c|}
\hline $\begin{array}{c}\text { TYPE OF } \\
\text { VOLUNTEER }\end{array}$ & GROUP I & $\begin{array}{c}\% \text { OF } \\
\text { TTL }\end{array}$ & GROUP II & $\begin{array}{c}\% \text { OF } \\
\text { TTL }\end{array}$ & $\begin{array}{c}\text { GROUP } \\
\text { TTLS }\end{array}$ & $\begin{array}{c}\% \text { OF } \\
\text { TTL }\end{array}$ \\
\hline TEACHERS & 24 & 18 & 8 & 16 & 32 & 17 \\
\hline TUTORS & 110 & 82 & 43 & 84 & 153 & 83 \\
\hline TOTAL & 134 & 100 & 51 & 100 & 185 & 100 \\
\hline
\end{tabular}

Group I: $n=7$, Group I: $n=7$

Within Group II there were reported to be a total of 51 volunteers providing ESL instruction. Of the 51,8 , or $16 \%$, were teachers and 43 , or $84 \%$, were tutors. Comparing the total figure of volunteers with the 103 students reported attending organizations in Group II, it can be seen that there was a student/volunteer ratio in Group II of 2.02:1.

The total number of volunteers reported to give ESL instruction in this sector of ESL providers was 185 . Thirty-two, or $17 \%$, were defined as teachers, and 153 , or $83 \%$, as tutors. The total students/volunteer ratio was $2.31: 1$. This indicates that the majority of students are being served in a one on one or small group environment.

Length of Service. Estimations on how long a person volunteers for a given program were reported to be a difficult item to approximate. Interviewees stated that this figure varied depending on the volunteers. On many occasions the average given was prefaced by an explanation that some volunteers serve longer than the average, and some shorter.

Given this qualification, within Group I it was reported that the most common time that a volunteer spent in a given program was 3 to 6 months. Six organizations reported this length of service. One organization reported an average service of one year. 
Group II reported a longer length of service than Group I. All organizations who stated that they could estimate the length of volunteer service reported an average length of attendance of one year or more.

The difference between the Groups indicates one of the largest differences throughout the study of the two Groups. It was noted that although the number of volunteers serving in Group II was much less than in Group I, those who did volunteer stayed much longer, normally over one year, whereas the volunteers of Group I were reportedly volunteering on a relatively short-term basis. This difference has a large impact on the management of an ESL program, and will be discussed in Chapter 5.

Recruitment. It was found that most organizations employed a variety of means for volunteer recruitment which included word of mouth, advertising or publicity in various newspapers, announcements in church bulletins, solicitation of various student groups such as high school students within language programs or college students within teacher training or cross-cultural training programs, volunteer associations, and sign-up sheets at various special functions. Table 8 depicts the means for teacher/tutor recruitment by Group I, Group II, and a total for both.

TABLE VIII

METHODS OF RECRUITING VOLUNTEERS BY GROUP

\begin{tabular}{|l|c|c|c|}
\hline \multicolumn{1}{|c|}{ METHOD } & GROUP I & GROUP II & TOTAL \\
\hline WORD OF MOUTH & 5 & 3 & 8 \\
\hline VOLUNTEER ASSOCS. & 4 & 1 & 5 \\
\hline STUDENTS & 4 & 1 & 5 \\
\hline CHURCH & 2 & 2 & 4 \\
\hline ADS/PUBLICITY & 2 & 0 & 2 \\
\hline SIGN-UP SHEETS & 0 & 1 & 1 \\
\hline
\end{tabular}

Group I: $n=7$, Group II: $n=6$ 
It can be seen that the most common means of recruitment by Group I was by word of mouth. The next most common means were either through solicitation of various student populations or through contact with volunteer associations. Following these means were the use of advertising and publicity in newspapers, and church bulletins.

Within Group II, again, word of mouth was the most common means of volunteer recruitment, followed by announcements in church bulletins, and finally by soliciting various students, and the use of volunteer associations; one organization recruited volunteers by providing sign-up sheets at various promotional functions.

Overall, eight organizations recruited by word of mouth, five by soliciting various student populations, five by contacting volunteer association, four by placing announcements in church bulletins, two by advertisement and publicity in newspapers, and one by means of sign-up sheets.

When asked to rate the following statement "Our current method of recruiting volunteers well suits our program objectives" on a scale of 1 to 5 , the average rating for Group I was 2.29. Group II's average response was 1.83 . The average rating for both Groups was 2.08, which indicates that overall, the respondents agreed that their methods of teacher/tutor recruitment well suited their program objectives.

Criteria for New Volunteers. It was found that there were several criteria described by the coordinators of both Groups. These were as follows: Communicative ability in the given students' native language, prior training, experience or displayed willingness to train, volunteer background checks by the coordinator, good English usage, and a variety of positive motivational characteristics such as willingness, sensitivity, and interest.

The most common criteria in Group I were prior training, experience or willingness to train shared equally with positive motivational characteristics. Four 
organizations each reported these criteria. The next most common criterion was a positive response on a background check, done after an initial interview with the coordinator. This was stated by two organizations. Finally, one organization reported that communicative ability in the student's native language was necessary.

Within Group II, positive personal motivational traits were reported to be the most common criterion for a potential volunteer. This was reported by three organizations. Next stated was prior experience, training, or a willingness to train, as reported by two organizations. One organization reported that ability in the student's native language was desirable, and one organization reported a need for the potential volunteer to display good English usage.

Overall, the most common criterion stated by both groups was desirable personality traits, as stated by seven of the organizations. The next most common, reported by six organizations was prior experience, training, or a willingness to participate in training. Both native language ability and positive background checks were reported as a criterion by one organization each. Table 9 summarizes the new volunteer criteria reported by the coordinators.

TABLE IX

CRITERIA FOR NEW VOLUNTEERS

\begin{tabular}{|l|c|c|c|}
\hline \multicolumn{1}{|c|}{ CRITERIA } & GROUP I & GROUP II & TOTAL \\
\hline PERSONALITY TRAITS & 4 & 3 & 7 \\
\hline TRAINING/WILLINGNESS TO & 4 & 2 & 6 \\
\hline L1 ABILITY & 1 & 1 & 2 \\
\hline BACKGROUND CHECK & 2 & 0 & 2 \\
\hline GOOD ENGLISH USAGE & 0 & 1 & 1 \\
\hline
\end{tabular}

Group l: $n=7$, Group II: $n=6$

Training. The coordinators interviewed reported a variety of means of volunteer training by their organizations. The majority of the training was found to be 
done initially, before the volunteer began tutoring/teaching. The means by which volunteers were reported to be trained included: required observation of other volunteers; various handouts created by Portland State University (PSU), PCC, and Oregon Literacy; referral to PCC to attend a training seminar and to obtain materials; training done in-house by the coordinator; monthly volunteer meetings in which tutor/teachers met to share ideas; and training from an outside party, in two cases arranged by PCC, in one case by a former staff member and professional ESL teacher, and in one case by Concordia English Language School. Also noted were two organizations which stated that training was non-applicable to their situation as the volunteers came qualified. Table 10 summarizes the responses given for tutor training.

TABLE X

VOLUNTEER TRAINING METHODS

\begin{tabular}{|l|c|c|c|}
\hline \multicolumn{1}{|c|}{ TRAINING METHOD } & GROUP I & GROUP II & TOTAL \\
\hline NONE & 2 & 2 & 4 \\
\hline OUTSIDE ON-SITE SERVICE & 2 & 2 & 4 \\
\hline HANDOUTS & 4 & 0 & 4 \\
\hline OBSERVATION & 2 & 1 & 3 \\
\hline TRAINED BY COORDINATOR & 3 & 0 & 3 \\
\hline REFERRAL TO PCC & 2 & 0 & 2 \\
\hline N/A & 0 & 2 & 2 \\
\hline TUTOR MEETINGS & 1 & 0 & 1 \\
\hline
\end{tabular}

Group I: $n=7$, Group I: $n=6$

The most common means of training stated by Group I was the use of handouts, which were reported to be used by 4 of the 7 organizations. This was followed by 3 organizations which reported training conducted by the coordinator. Two organizations each reported training by means of observation, referral to PCC for training, and volunteer training by non-organizational trainers who came to the organization to train 
the volunteers. One organization held monthly volunteer meetings; two organizations stated that no training was offered.

Within Group II, it was reported by two organizations that an outside organization had been used to train their volunteers. One organization reported the requirement of observing another volunteer before the new volunteer began. Two organizations reported that training was not applicable to their situation, and two organizations provided no training.

The combined totals for both Groups indicate the handouts and outside trainers were equally utilized, as stated by four organizations each. Observations and training provided by the coordinator were the next most common means, as indicated by three organizations each. Two organizations referred their volunteers to the PCC training tutor seminar. Monthly volunteer meetings were held by one organization in order for the volunteers to meet and share ideas. A total of four organizations reported providing no training at all, and two organizations stated that the question was not applicable to their situation.

When asked to rate the following statement "Our current method of training volunteers well suits our program objectives" on a scale of 1 to 5 , the average rating for Group I was 2.29. Group II's average response was 2.33. The average rating for both Groups was 2.31, which represents a response tendency of slightly below agreement that the methods of volunteer training well suit program objectives.

Tracking. It was found that three organizations in Group I tracked their volunteers by periodic phone calls. Two organizations reported the use of forms to track and maintain records of their volunteers. Within Group II, three organizations used telephone calls, and one used forms. Overall, six of the nine organizations who tracked their volunteers did so by periodically phoning their volunteers and "checking in" with them or updating their information. The remaining three organizations used 
an in-house form to maintain records of their volunteers. It was stated by one coordinator that their tracking methods would soon be more formalized due to a requirement on a new pending grant. Table 11 summarizes the methods of tracking volunteers by group.

TABLE XI

METHODS OF TRACKING VOLUNTEERS

\begin{tabular}{|l|c|c|c|}
\hline \multicolumn{1}{|c|}{ METHOD } & GROUP I & GROUP II & TOTAL \\
\hline CALL FROM PHONE LIST & 3 & 3 & 6 \\
\hline NO SYSTEMATIC METHOD & 2 & 3 & 5 \\
\hline USE FORMS & 2 & 1 & 3 \\
\hline
\end{tabular}

Group I: $\mathrm{n}=7$, Group II: $\mathrm{n}=7$

When asked to rate the following statement "Our current method of tracking volunteers well suits our program objectives" on a scale of 1 to 5 , the average rating for Group I was 1.86. Group II's average response was 1.33 . The average rating for both Groups was 1.62 , which indicates that overall, there was strong agreement that tracking methods well suited the given organization objectives. This rating indicates the strongest agreement of any of the aspects rated in this portion of the questionnaire. Rating Practices to Educational Objectives.

Table 12, shown below, summarizes the results from the portions of the questionnaire which asked the coordinators to rate their particular practices to the objectives of their program. Each statement was phrased such that by agreeing with the statement, the coordinator indicated that they were satisfied with their current practices. Thus, the lower the score for a particular question, the more strongly in agreement was the coordinator. For example, in the first statement, "Our current method of student recruitment well suits our program objectives", a rating of 1 would indicate that the coordinator strongly agreed with this statement. A rating of 5 would indicate that 
he/she strongly disagreed, and a rating of 3 , indicates that he/she was neutral on this subject. Table 12 summarizes the average responses by Group and overall total. Group I responded to all questions of this type, although in most cases, various coordinators in Group II did not wish to rate their practices in a given area as they did not feel it was applicable to their program. The number of responses received for the given statement is indicated in parentheses for each area.

\section{TABLE XII}

AVERAGE RATING OF PRACTICE TO OBJECTIVE

\begin{tabular}{|l|c|c|c|}
\hline \multicolumn{1}{|c|}{ PRACTICE } & GROUP I* & GROUP II* & TOTAL* \\
\hline TRACKING VOLUNTEERS & $1.86(7)$ & $1.33(6)$ & $1.62(13)$ \\
\hline STUDENT RECRUITMENT & $1.86(7)$ & $2.20(5)$ & $2.00(12)$ \\
\hline VOLUNTEER RECRUITING & $2.29(7)$ & $2.33(6)$ & $2.08(13)$ \\
\hline STUDENT ASSESSMENT & $2.14(7)$ & $2.33(6)$ & $2.30(13)$ \\
\hline VOLUNTEER TRAINING & $2.29(7)$ & $2.33(6)$ & $2.31(13)$ \\
\hline TRACKING STDNT ED PROGR. & $2.64(7)$ & $2.00(7)$ & $2.32(14)$ \\
\hline
\end{tabular}

* Parenthesis indicates number of responses per group.

The range of response to this type of question was from 1.33 to 2.64 . In no instance did any single area receive an average response rating of less than a neutral statement, and there were no areas that evoked an average rating of disagreement. It was found that the highest average score, 2.64 (indicating the least agreement with the statement) was given by Group I in the area of the organization's methods of tracking their students' educational progress. The lowest average score, 1.33, (indicating the strongest agreement) was seen in Group II in the area of tracking volunteers.

By ranking responses in order of strongest agreement to disagreement, it can be seen that within Group I, methods of recruiting students and tracking volunteers showed equally highest agreement with scores of 1.86. Slightly less strong in agreement was assessment techniques at 2.14 , which indicates a response rating of 
slightly below agreement. Means of recruiting and training volunteers were rated as 2.29 , and the area showing least agreement was the organizations' methods of tracking students' educational progress, at 2.64. Figures 3 and 4 summarize the ratings for Groups I and II respectively.

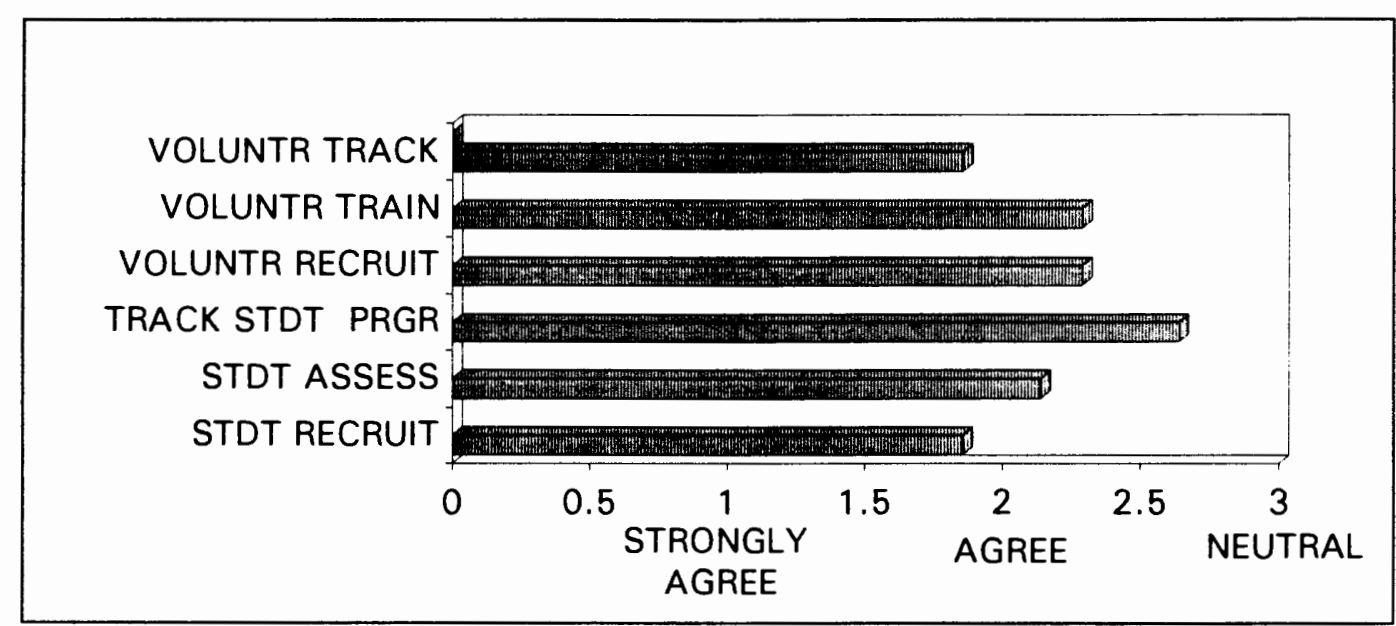

Figure 3. Average rating of practice to objective for Group I

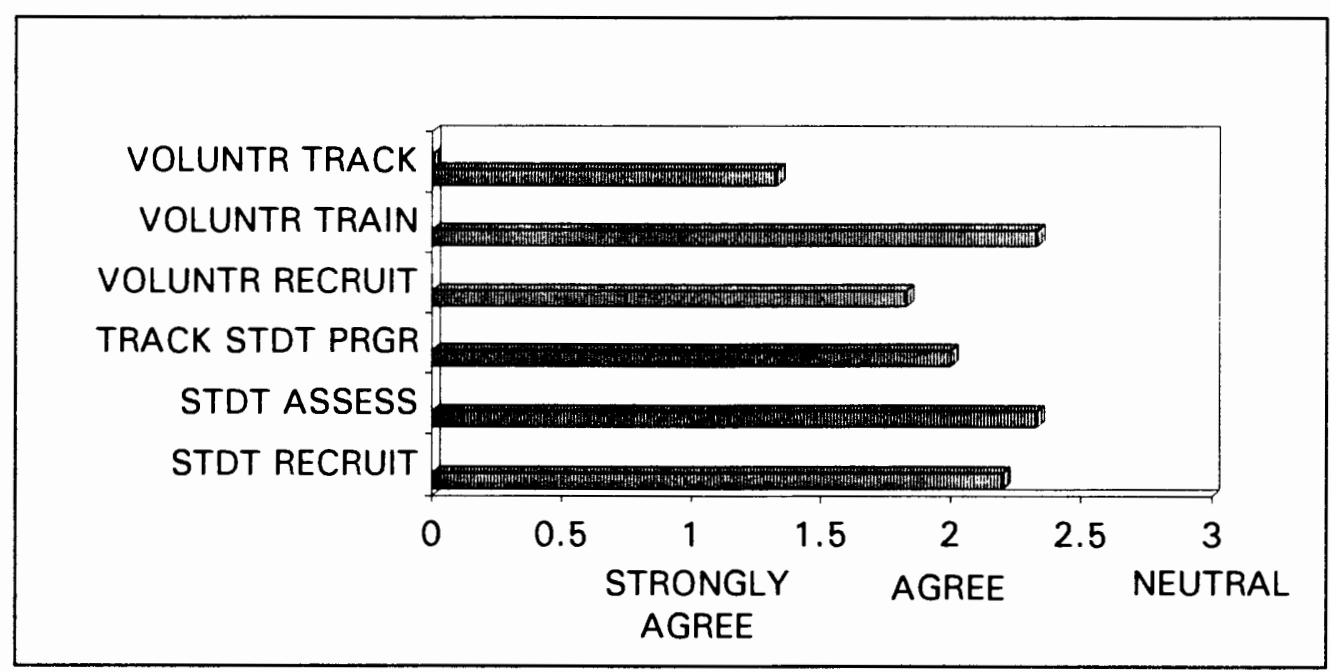

Figure 4. Average rating of practice to objective for Group II 
Within Group II, the area of strongest average agreement was the organizations' means of tracking volunteers, scoring 1.33. Respondents rated methods of recruiting volunteers as 1.83 , closely followed by methods of tracking students' progress, at 2.0 . In these three areas, respondents all agreed or strongly agreed that their practices well suited their objectives. They rated methods of student recruitment as 2.20 , student assessment techniques and volunteer training rated as 2.33. Figures 3 and 4 summarize the average ratings for Groups I and II respectively..

Overall, ratings from both Groups, ranked from strongest agreement to least, are as follows: tracking volunteers (with an average score of 1.62), recruiting students (2.0), recruiting volunteers (2.08), student assessment techniques (2.30), training volunteers (2.31), and tracking student's educational progress (2.32). The latter three areas, student assessment, volunteer training, and tracking student's educational progress, were all rated, on an average, between neutral and agreeing. Although by no means showing disagreement, comparatively speaking, these three areas on an overall average were rated weakest in terms of the given organization's practice satisfying their program objectives.

Rating the Value of Support Services Made Available.

Table 13 shown below summarizes the results from the portion of the questionnaire which asked the coordinators to rate the value of a given support service made available. As in the above section, this rating system was done on a five point scale, with 1 indicating an opinion of very valuable, and 5 indicating not at all valuable. Group I responded to all questions of this type, although in Group II, one organization was not interested in receiving additional support services, and did not wish to rate the value. Therefore, seven out of seven organizations in Group I responded, whereas six out of seven responded in Group II. 
TABLE XIII

AVERAGE RATED VALUE OF SUPPORT SERVICES MADE AVAILABLE

\begin{tabular}{|l|c|c|c|}
\hline \multicolumn{1}{|c|}{ SUPPORT SERVICE } & GROUP I & GROUP II & TOTAL \\
\hline VOLUNTEER TRAINING & 1.43 & 2.33 & 1.85 \\
\hline MATERIAL RECOMMENDATIONS & 1.43 & 2.33 & 1.85 \\
\hline VOLUNTEER RECRUITING & 2.14 & 1.67 & 1.92 \\
\hline GRANT \& FUNDING INFORMATION & 1.71 & 2.17 & 1.92 \\
\hline STUDENT EVALUATION & 2.43 & 2.50 & 2.46 \\
\hline
\end{tabular}

Group I: $n=7$, Group II: $n=6$

The range of response to this type of question was from 1.67 to 2.50 . In no instance did any single area receive an average response rating of less than a neutral statement, and there were no areas that evoked an average rating of not valuable. It was found that the highest average score, 2.50 (indicating the least perceived value of the service) was given by Group II in reference to recommendations on methods of student evaluation. The lowest average score, 1.67, (indicating the highest perceived value) was seen in Group II in reference to recruiting volunteers.

By ranking responses in order of strongest perceived value to weakest, it can be seen that within Group I, tutor training seminars and instructional material recommendations showed equally highest perceived values with scores of 1.43. Next highest in value was grant and funding information averaging a score of 1.71 . Recruitment of volunteer tutors rated as 2.14 , and the area depicted as least valuable was recommendations on methods of student evaluation, at 2.43. Figures 5 and 6 summarize the ratings for Groups I and II respectively. 


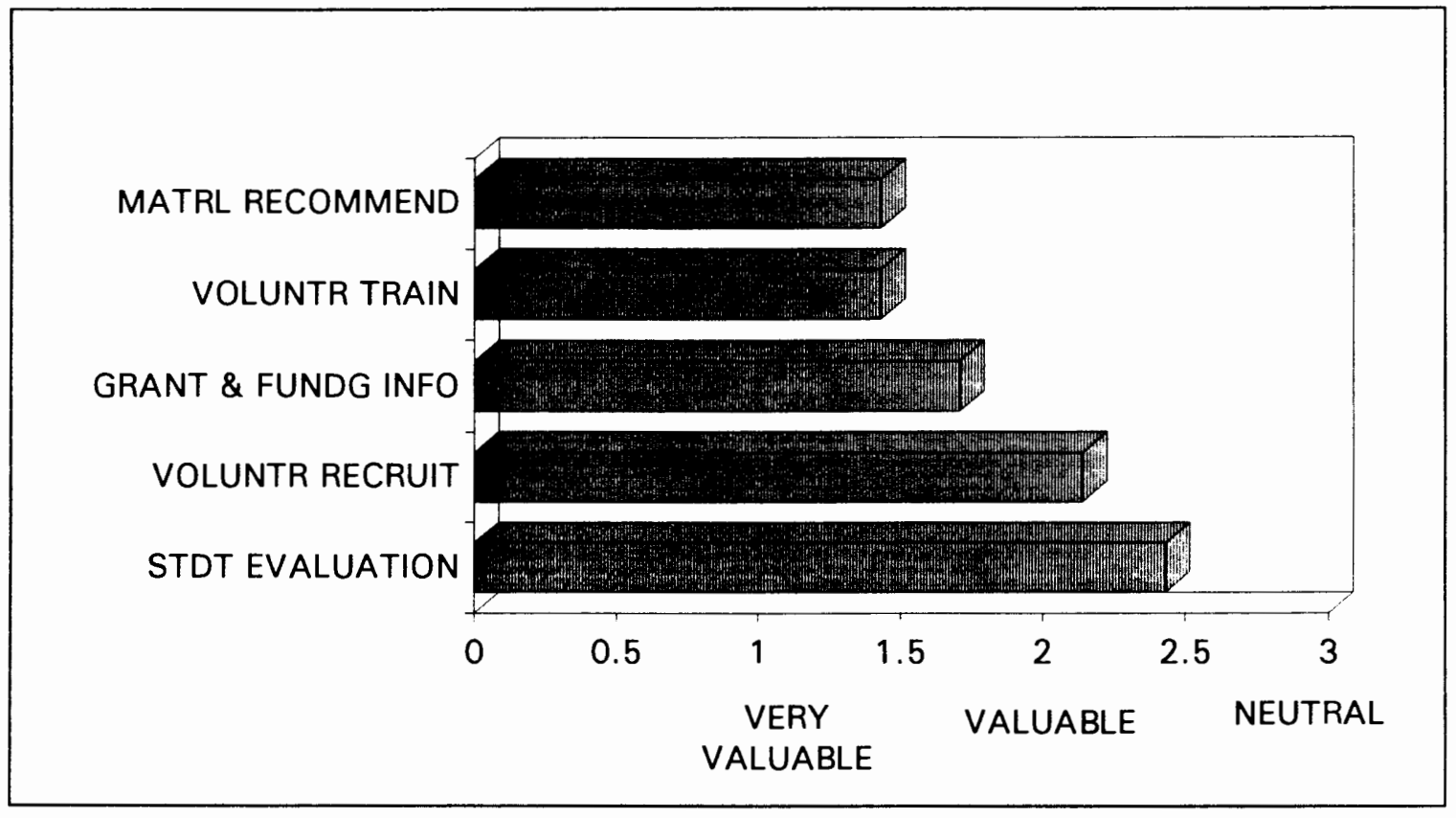

Figure 5. Average rated value of support services made available for Group I

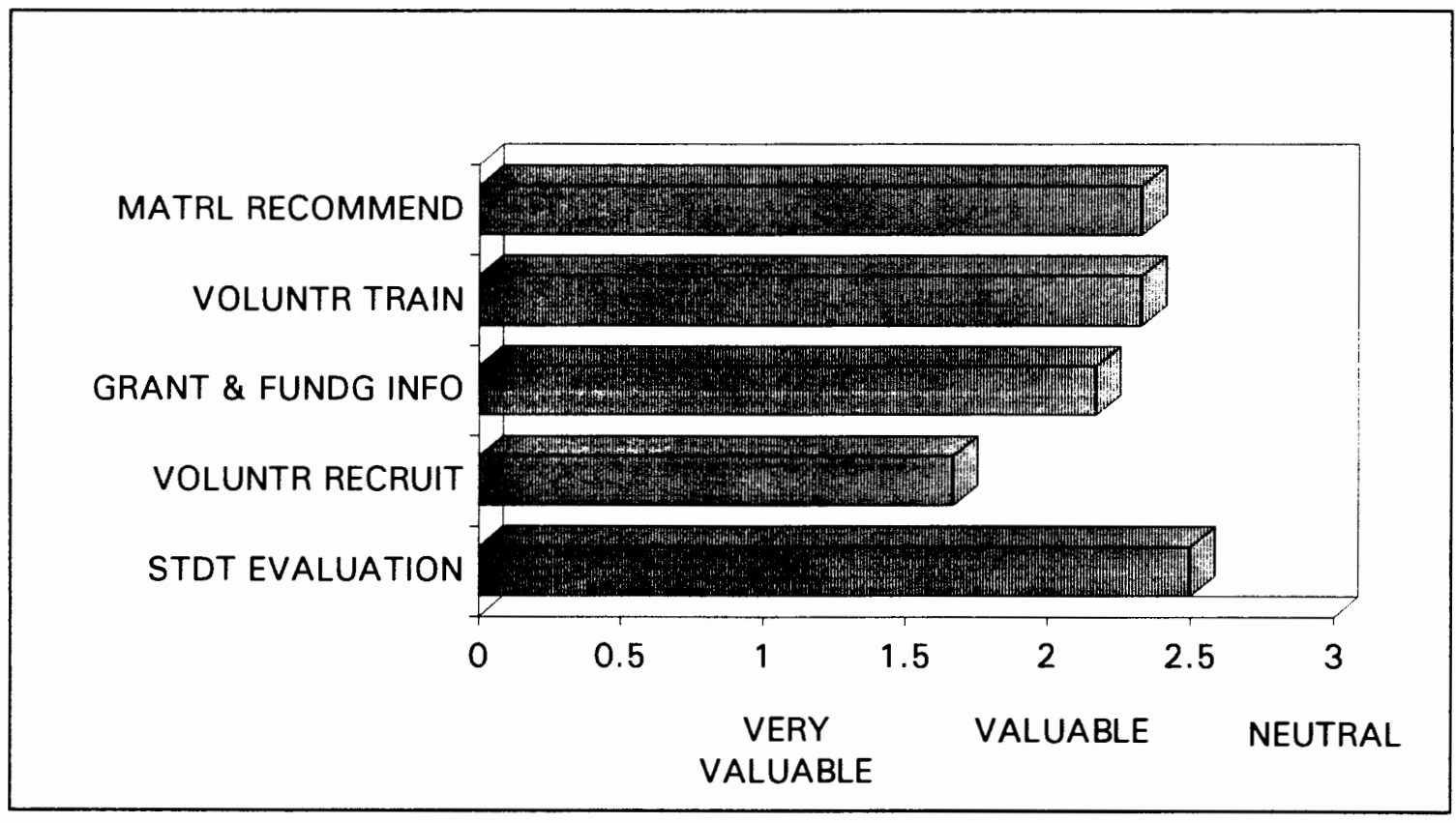

Figure 6. Average rated value of support services made available for Group II

Within Group II, the average area of strongest perceived value was the support service of recruiting volunteers, rated at 1.67. Ratings of other support services were 
as follows in order of perceived value: grant and funding information, at 2.17 , tutor training seminars and instructional material recommendations, each at 2.33; and finally recommendations on methods of student evaluation, rated as 2.5 .

Overall, ratings from both Groups, ranked from highest perceived value to lowest, are as follows: tutor training seminars and instructional material recommendations (both averaging a rating of 1.85), grant and funding information and recruitment of volunteer tutors (1.92 each), and recommendations on methods of student evaluation (2.46). Total averages indicate that all support services mentioned are perceived as valuable with the exclusion of recommendations on methods of student evaluation.

Other support services mentioned as being of value were as follows: on-site volunteer training; publishing a monthly volunteer newsletter which gives teaching suggestions and ideas; and establishing an organization which could grant tutors recognition for their services and provide a way of promoting the cultural exchange between students and volunteers by organizing periodic events.

\section{DETAILED ORGANIZATION PROFILES}

The following are the results from the class observation/teacher interviews conducted with four of the organizations. The purpose of these observations was to obtain a better understanding of the approaches, methods, and materials being used within the classroom, and also, when possible, to describe some of the practicing volunteer teachers. Whereas the Coordinator Interview attempted to describe the organizations on a program level, the observations were conducted in order to describe the programs on a classroom level. Each organization is first summarized with background program information given by the coordinator or lead teacher. This information is then followed by a descriptive narration taken from the notes generated 
from the observation/interview. First presented are Organizations $\mathrm{C}$ and $\mathrm{G}$ from Group I, followed by Organizations $U$ and $Y$ from Group II. In all cases, pseudonyms have been used and students' ethnic background and native language have not been stated in order to provide anonymity. The students' native language has been referred to as their first language (L1).

\section{Organization $\mathrm{C}$}

Background Program Information. Organization $\mathrm{C}$ provides a variety of services for its clients. These services include a bilingual after school program for children, an ESL program for adults, an ESL video tape program, and a mental health program. As stated by the coordinator, the long term goal of the ESL program is to teach students how to learn, that is, to prepare students with the basics of pronunciation, vocabulary, and instruction in using a dictionary, stressing practical English for every-day life. In all areas of self-evaluation of rating program practices in relation to satisfying program objectives, Mr. Smith rated the organization as strongly agreeing, with the exception of methods of recruiting volunteers, in which he agreed that the current methods of recruiting volunteers well suited his program objectives.

At the time of the interview, Organization $C$ was serving approximately 40 students in classes, and occasionally tutored on a one on one basis those very beginning students in the area of pronunciation. An average student remained with the program 2 to 3 years or until they received a job, in which case they often changed to the video tape program. The video tape program consists of a graded series of English language learning tapes entitled Speak to Me. Students check these tapes out for a week at a time, working independently through the tapes from beginning level to advanced.

Initial student evaluation was reported to be done by testing and evaluation by the coordinator. Students' progress was tracked only through self-evaluation. There were no formal methods for this. 
It was stated that Organization $\mathrm{C}$ was staffed with four volunteer teachers. Teachers were recruited usually through the Portland State University TESOL program, or through the American Association of Retired Persons (AARP). Teachers were required to have experience, or to have trained with Oregon Literacy. In addition, the coordinator provided teaching ideas, materials, and guidance throughout the teaching process. Teachers varied in their length of stay. For those who were from a teacher training program such as through PSU, the average length of service was one term, or 3 to 4 months. Others teachers had been involved for more than 4 or 5 years.

Classroom Observation. The researcher visited this site one evening and was first given an interview with the program coordinator. Mr. Smith explained to me his system of instruction. As previously stated, his goal is to instruct beginning students in the area of how to learn a language, so that they may eventually access the other language programs available in the Portland area. This is done by first teaching the basics of pronunciation, with emphasis on using a dictionary and instruction in the phonetic system presented in the dictionary. The objective is to provide the students with the ability to find and pronounce any word in the dictionary. After these skills have been gained, the students are then presented with common vocabulary. That is, Mr. Smith has various lists of common English vocabulary words, and these words are taught, building on them in order to allow students to use them primarily on a sentence level. Following this is instruction on conversation. Reading and writing are the final skills presented.

In addition to the vocabulary lists taken from various standard American English dictionaries, materials used for instruction included using the "Key to English" section provided in the Wednesday edition of the local newspaper, The Oregonian; materials from Oregon Literacy, specifically those published by the Laubach organization; and realia. 
After speaking with the coordinator, I entered the classroom. It was a large room with four tables placed into the shape of a rectangle. Nine students, seven women and two men, sat around the table, and the teacher, whom I will refer to as Beverly, stood at the front, giving instruction using a chalkboard. In front of Beverly on the table were L1/English dictionaries and a thick, worn teacher's manual designed for volunteer teachers by the Laubach organization. A coffee pot sat on a chair behind the students, and hot tea was brewing.

The apparent objective of the first lesson was the presentation of direct and indirect questions. Written on the board were the following sentences:

Where's the bank?

There's a traffic cop.

Let's ask him where the bank is.

Where's First Street?

There's a traffic cop.

Let's ask him where First Street is.

Students produced choral repetition of these sentences. Explanations were given in the students' $\mathrm{L} 1$ as to details of this grammar.

The next activity consisted of the teacher putting several blocks on the board which represented a map. The teacher explained the task in the L1. Each student individually came to the board and asked "Where's the bank?". The teacher read directions and the students followed these directions on the board, marking an " $\mathrm{X}$ " and his/her initials by the " $\mathrm{X}$ " where he/she thought the bank was. This continued with all of the students, using the same directions. After all students had finished, Beverly read and followed the directions herself, indicating the correct answer. The students appeared to enjoy this activity, and there were chatter and laughter during the activity.

Following this, students were individually drilled on the use of indirect questions. For example, Beverly would say, "where's the bank...traffic cop", or "where's the supermarket...woman", and the student was required to produce an 
indirect question using these prompts, changing the pronouns appropriately. At this point, error correction was very rigid, especially with pronunciation of vowel sounds when incomprehensible. Correction was done in the students' L1.

A quick drill followed, practicing the use of "there are" versus "there is". This again was done individually around the table, the teacher drilling and correcting.

Next a presentation of reported speech using Wh- question words was given. This was done by writing the following sentences on the board:

Jim, turn left now.

I told Jim when to turn.

Jim, turn left at the next corner.

I told Jim where to turn.

Sue, buy a half-gallon of milk.

I told Sue how much milk to buy.

Sue, buy three apples.

I told Sue how many apples to buy.

Beverly stood aside and allowed the students to copy these sentences into their notebook. Using a pointer, she then conducted a choral repetition, asking individual students to translate each line into the L1. Using the L1, the teacher then explained the difference in use of "how much" and "how many". Individual drilling followed, checking for correct pronunciation. Students were then dismissed for a break.

After the break, Beverly wrote the followings sentences on the board:

A car must stop at a red light.

We must eat every day.

We $\underline{\text { must }}$ sleep every night.

She said as an aside to me that the students knew all of the words in these sentences with the exception of "must." This was a presentation of the word "must." Choral repetition was performed with these sentences, and then individuals read the sentences and were drilled changing the pronouns from "we" to other ones such as "he," "they," etc. Students were then individually drilled on various other phrases 
using "must." For example, Beverly would call on a student, say "read English," and the student would say, "You must read English every day."

The final activity of the night consisted of reading from a graded reader from Oregon Literacy. The title of the story read was "City Traffic." At the top of each page of the book was a block with new vocabulary. These words were first explained. Then the reading proceeded by each student reading aloud one sentence each. Pronunciation was checked and after each line was read, the student then said the line in their L1. Questions from other students arose if the meaning was unclear. These questions and explanations were conducted in the L1.

The second time through the text, students repeated in chorus after Beverly, line by line. She then asked reading comprehension questions and the students answered. The third time through the text, students read one paragraph each. The students obviously knew the reading routine, as after the passage was completed, they immediately returned to the beginning of the passage, before Beverly said to do so. The students' reading was loud and sure. There was no mumbling or shyness. Pairs of students were quietly discussing the reading together as the activity progressed.

During the break I got a chance to talk with Beverly. She related that she was a retired Internal Revenue Services employee who has been tutoring ESL since 1986, and had now been teaching classes for two years. During her employment years, while working with tax returns she noticed a strong relationship with low income, and the apparent English writing abilities of the person filing their returns. For this reason, when she retired she chose to work in literacy training. She completed both the ESL and Adult Basic Education (ABE) training at Oregon Literacy. Beginning as a one on one tutor, she became very popular, and other students wanted to be tutored by her also. Two years ago, she became associated with Mr. Smith and had been teaching 
classes ever since. She had an advanced class two nights a week, and she taught this class, the beginners, on two other nights each week.

Beverly stated that she was strict with her attendance, stressing to the students that they must attend or they could not remain in the program. Students were charged a minimal fee to attend, but more importantly, they knew they must come as other students would welcome the chance to attend her class, but there was no vacancy. She did not allow open entry/open exit in her classes. For this reason, students in each class were at relatively the same English proficiency. She also did not allow her classes to be larger than a "manageable" size, i.e. more than 12 people.

Materials used for this class and the advanced class came from Oregon Literacy. Students had their own texts, readers, and workbooks. These had been purchased by Beverly and the students reimbursed her. Beverly explained that upon initially receiving her ESL materials from Oregon Literacy, she went through each source matching and planning the use of her resources. This initial organization allowed her to teach now with no preparation beforehand. She showed me a copy of her teacher's manual, marked with paper clips and extensive notes, and explained that she had a room in her house in which she had organized her supplemental materials, and now only had to pull the file or box when needed.

Beverly was proud to provide a very relaxed atmosphere. Her class was a place where students came to fraternize. The pace was never rushed and she said that often class was canceled for holidays and birthdays so that they could all go to dinner together to eat and talk. She also stressed the fact that in her class, students were never presented a new structure without first knowing the vocabulary. Many of her students were from other larger ESL programs and she stated that they often had voiced a feeling of being lost and confused in the other programs. Within her class, she tried to control the lesson so that students always understand the vocabulary before they learn 
the structure. Also she stated that she understood that individual drilling took a good deal of time, but that her students had expressed that they felt it was important and something they often did not get in the other programs they had previously attended.

Overall, the class lasted approximately $21 / 2$ hours. Instruction was very structured, consisting almost entirely of drilling, and was completely teacher-centered. At no time were the students engaged in pair work activities. It must also be noted that throughout the entire lesson, English was studied as a subject, and not approached as a means of communication. That is, the means of communication was always in the student's L1, and no free speaking activities were noted. During the break and throughout class, students never spoke to one another in English, only in their native tongue.

\section{Organization G}

Background Program Information. Organization $G$ is a Volunteer Agency whose function is to assist in refugee resettlement. It was reported to provide a variety of services including case management, and sponsor development. Included in these services was the provision of ESL services. The long terms goals of the ESL program were reported as not yet explicitly articulated, but the coordinator stated that at present she was working to maintain the program as it was, and hoped to improve services and increase the number of students served in the future.

In four of the six areas of self-evaluation of rating program practices in relation to satisfying program objectives, the coordinator disagreed that the practices well suited the objectives. These areas were in student assessment techniques, methods of tracking students' educational progress, recruiting volunteers and volunteer training practices. Methods of student recruitment and methods of tracking volunteers were rated at neutral in terms of well suiting the program's objectives. 
At the time of the interview, Organization $G$ was serving approximately 40 students which included refugee populations and Hispanics. This was done by one on tutoring, small group instruction, and classes. An average student remained with the ESL program for 6 months, although many remained much longer.

Initial student evaluation was done by the volunteer, and was reported to be conducted by informal assessment methods. It was reported to be the responsibility of the individual volunteer to track the students' educational progress.

Organization $G$ was staffed with nine volunteer teachers, and five tutors. Normally volunteers contacted the coordinator, and it was stated that very little recruiting was conducted, although occasionally contact was made with the PSU TESOL teacher training program. Volunteers were permitted to teach or tutor without prior experience. During the initial informal interview with the coordinator, they were required to show interest. Volunteer training was conducted by distributing limited materials created by PCC and PSU, and inexperienced teachers were teamed with those teachers who had experience. New volunteers were also referred to PCC for their tutor training seminars. Volunteers were reported to remain with the program for an average of 6 months.

The coordinator described the teaching approaches used by the various teachers as a mixture of techniques, and student directed. The organization provided Molinsky

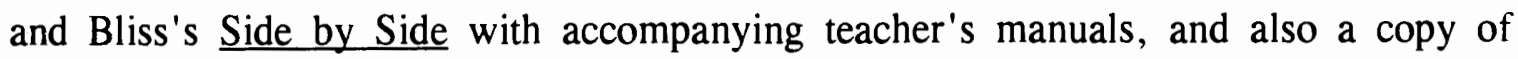
$\underline{V}$ istas with a teacher's manual. Teachers also were reported to provide and use their own materials, and many various materials had been donated to the program.

Classroom Observation. The researcher observed one of the night classes which were reported to be held three nights per week from 7:00 to 9:00. The beginning level students were divided and team taught by three teachers. The advanced level class, the one observed, was held in a separate room, and taught by one teacher. The researcher 
arrived to find several students moving from one classroom to the other. The class which was scheduled to be observed had no teacher present, so the researcher moved to the other classroom. There were approximately nine students seated and the teacher who was to be observed, Mary, was talking to some of the students, explaining to them in the students' L1 that there would be no classes the following Monday due to its being Valentine's Day. There was joking and laughter about this. Mary stayed in this classroom until another teacher arrived at approximately 7:10. As we were walking to the other classroom, two more teachers arrived.

The advanced class consisted of six men. One of them was a police officer who was paid to take classes as part of his patrol duty. As the police officer entered the classroom, he said, "OK everybody, you're under arrest," which produced laughter in the rest of the students. Also in class was another visitor who had been a teacher for the program approximately 6 months earlier, and with her was a former student. There were greetings and hugs exchanged by the former teacher and student and the current teacher.

The classroom was provided by the Oregon State University (OSU) Extension Center, and doubled as a clinic during the day. The front room was used as the classroom. It was small but cheerful, with red carpet and two narrow tables covered with red and white table cloths. There was a bulletin board on the wall with a Valentine's Day theme. Students sat haphazardly around the tables, some facing each other, and some facing the front. There were L1/English dictionaries and Yellow Page phone books on each table. It was later learned that if a student attended class 10 times, they received a free $\mathrm{L} 1 /$ English dictionary.

The class began at approximately 7:20 with introductions all around. Soon another student entered. The slang vocabulary "Hang on a sec," Hold on," and "Wait up" was explained. Both L1 and English were used for this explanation. 
Students were then put into three groups. Using The Yellow Pages of the phone book students were required to find the names, addresses and phone numbers for the following items, which were written in marker on a large pad of paper located at the front of the room:

A Unitarian-Universalist Church in N.E.

A copy service in S.W.

A jeweler in S.E.

A tire company in N.E.

A paint store in S.E.

A Mexican restaurant in S.E.

Students appeared to understand the task and worked immediately without appearing confused or unsure. A mixture of the L1 and English was used by the them to accomplish this task, most students using a combination of both. A few minutes later, three people from OSU entered the room moving tables into a back room of the classroom. Soon, Mary ran to the other classroom to give the teachers a T-shirt which they were going to use as a prize. Upon returning, Mary required a member from each group to write the desired information on the pad of paper at the front of the class. While students were doing this, Mary entertained the students by singing a song in the student's L1 and asking the students to translate the words into English. This progressed into a discussion of different and favorite musical groups. The discussion was in English, and there was much laughing, bantering and singing by the students. Upon completion of the task, Mary discussed the importance of using The Yellow Pages to find establishments that were conveniently located .

The next activity consisted of vocabulary building by means of reading 10 words in the student's L1, and having them translate them into English. The list of words was as follows: "better," "to belong," "the bill," "bone," "to be born," "bracelet," "broil," "brush," "burn," and "busy." These words were taken from Mary's textbook which she uses to study the student's L1. Mary reported that she 
generally used her L1 textbook as she had not found an ESL text which suited her purposes. Some of the students wrote these words in their notebooks only in English, while others wrote them in their L1 and waited for the discussion to complete the words in English. There arose from this a discussion of contrastive analysis of spelling and pronunciation of four English consonant sounds. Mary stressed the importance of pronunciation by giving various homophones to illustrate areas of confusion.

The next activity consisted of Mary saying "How are you?" and each student had to answer telling "the truth, " not just saying "fine." Responses were written on the pad and discussed. The students were then asked if there was anything they wished to learn or discuss in particular. One student said he wanted some coffee; thus a 10 minute break was announced.

When everyone returned Mary wrote the following five sentences from her L1 text on the pad, and the students were required to write the translations in their notebooks. The sentences were as follows:

Albert lives in Bogota, the capitol of Columbia, with his family.

$\mathrm{He}$ is very charming and intelligent.

He studies English in school and speaks very well.

At home, Beto speaks Spanish with her mother and father.

Beto's father works in a bank and his mother works in a hospital.

Students were then required to take turns writing their translations on the pad. There was a large amount of peer correction during this activity. While the students were doing this, another police office partially entered into the room and spoke with Mary. She left briefly to talk to him outside.

The class concluded with a 2 to 3 minute discussion of a particular vocabulary word, "halo," and the equivalent in the students' L1. Shortly after 9:00 class was dismissed although it took many of the students approximately 10 minutes to leave. There was a continuation of the joking and bantering between the teacher and the students. 
The researcher met with Mary at a nearby coffee shop afterwards in order to discuss in more detail some of her background and practices. Upon arriving two of her students appeared and sat nearby. Mary devoted most of her attention to the students, discussing specific vocabulary and pronunciation. Mary had been teaching in this organization for more than two years. She stated that she worked full-time during the day, and volunteer taught three nights per week now that her son had moved to Europe. Although not explicitly stated, it was apparent that Mary was interested in the culture of the people she taught. She was actively studying their language, and vacationed in the country from which most of her students had come.

Overall, it must be noted that this class was surrounded by a very social atmosphere. Also, there appeared to be a lack of structure. There were people coming and going, continual interruptions, and on-going bantering, laughter, and joking. These interruptions did not appear to surprise the students or teacher, but seemed to be accepted as commonplace occurrences. The lesson seemed to be given spontaneously, often taking the course directed by the students or the whim of the teacher. Within this unstructured and seemingly chaotic format, there was ample opportunity for free conversation, and the majority of the instruction was in English. Students used both English and their L1 as the means of communication with the teacher and with each other.

\section{Organization U}

Background Program Information. Organization $U$, a language program through a church organization, had been in existence for $21 / 2$ months when first interviewed. The lead teacher/program coordinator, Larry, stated that the long term goal for the ESL program was to provide continuing service for new members of the ethnic community served by this church. The majority of areas in which the coordinator self-evaluated the practices of the organization with the objectives of the 
program were answered with a rating of strong agreement. These areas were in student and volunteer recruitment, teacher training practices, and methods of tracking volunteers. Ratings of disagreement were given for methods of student assessment and tracking students' educational progress.

Organization U served approximately 20 students at the time of the interview, and this was done entirely through classes. Since this program had only been in existence for $21 / 2$ months, the coordinator was not able to estimate the average number of months that students attended the program. Initial student assessment was done by presenting an introductory lesson in which assessment was integrated into the lesson. This lesson included both language proficiencies and also the goals of the students. From the abilities displayed by the students during this session, they were grouped into a beginning and advanced class. It was also stated that assessment was an on-going continuous process, although the formalized method of tracking students' educational progress had not yet been established. Tracking the students' educational progress was reported to be done by periodically introducing reading material at specific levels, and through questions and answers noting who was able to talk about the reading.

At the time of the interview there were reported to be two volunteer teachers. The program had been founded by Larry, and through word of mouth, another teacher, whom I will call Tom, joined him. It was stated that the necessary criterion for teaching in this program was the ability to be extremely flexible and willing to survive interruption due to the open entry/open exit policy of the program. It was also important to be able to work with shy students. Both of the teachers of this program were students of PSU's Teaching English to Speakers of Other Languages (TESOL) Program, and the teaching they were doing fulfilled their course requirements. Both teachers planned to volunteer with this program for a minimum of 5 additional months 
The coordinator described their program's teaching approach as using a mixture including Total Physical Response (TPR) and a "Semi"-Audiolingual. Materials used were provided by the teachers, and they included handouts, realia, and a large pad of paper with markers.

Classroom Observation. Classes were held once a week before mass in the church hall, which was also used for other church functions. It was a large, warm, well-lit room with 20 tables covered with a thick red vinyl. It was immaculately clean and orderly. There were bud vases with artificial flowers and napkin holders on each table, red chairs around each table, and red carpeting. Pictures of various religious figures were hung on the walls, and there was a large kitchen at one end of the room.

A few minutes before class began, Tom played a little jazz piano while waiting for the rest of the students to arrive. Five students were already seated at one of the rectangular tables, and they were reviewing their handouts and talking to each other in their L1, although occasionally, one of the students translated to Larry what they were laughing about.

Ten minutes passed and the teachers talked amongst themselves discussing the logistics of the class that night. Tom had to leave early, and some of the advanced students had not arrived; therefore, they decided to teach both groups together.

Tom shortly thereafter began telling a story to the class and introducing politeness strategies through examples of this story. One more student arrived to make nine, and he began the class. Two teenage girls arrived and sat at another table to study. I assumed that these were daughters or relatives of one of the students.

The lesson presented was the simple present tense, with special emphasis on the third person singular. Tom presented this using a large pad and marker which he rested on his knee. Students had notebooks, and a few took notes. Tom chose a few random students to make sentences using pronouns. Although he corrected errors on 
his pad, he did not overtly correct the students. After several examples had been written on the pad, he explained the rule in English. Next, a handout was distributed for controlled practice of the lesson. The task was explained and the first sentence was done as an example. Students worked in pairs to complete the task. Both Larry and Tom circulated and helped individuals by explaining vocabulary and correcting errors. The medium of communication among the students was in their L1, but the teachers used only English.

The worksheet activity took about $1 / 2$ hour although the more advanced students finished much sooner. One of the more advanced students moved to another student and helped her. Two additional students arrived, with apologies, at the time when Tom was beginning to review the worksheet with the entire class. They sat at the next nearest table, quietly listening. Tom asked for volunteers to read aloud each sentence. Again he never overtly corrected pronunciation or grammar, although he did repeat each sentence, stressing the correct forms.

Tom explained to the class that he had to leave, and then Larry began teaching. Larry opened with a communicative activity in which he used several pictures to elicit a story, which the students were required to guess. There were pictures of a man, a woman, two people eating dinner, flowers, a wedding, a baby, a night scene of a city, a house, and a car accident. Larry first asked the students to give the man and woman names. He then pantomimed and encouraged the students by pointing to the pictures, to tell the following story (the names used were those chosen by the students):

Stan invited Marilyn to dinner. After dinner, he bought her flowers. Marilyn fell in love with Stan. Later, they had a wedding. Afterwards, Marilyn had a baby. Then Stan started drinking too much. He never took her to restaurants, and he stayed out all night, while Marilyn stayed home with the baby. Stan got in a car accident. Marilyn kicked Stan out of the house. They got a divorce. 
The students all participated in this activity and they appeared very interested. There was a good deal of peer correction, although it was unclear exactly what grammatical forms were actively being sought by Larry. After eliciting the entire story from the students, Larry then repeated the story reviewing the forms in more detail, and discussing specific idioms and grammar. This led into a discussion of weddings and wedding dates of various students allowing Larry to present forms and pronunciation of ordinal numbers. He also explained the difference between a wedding and a marriage.

The next activity consisted of asking two volunteers to come to the front of the class. Larry gave the students one picture to look at and explained to them that one person was to describe the picture in great detail. The other student also had to describe the picture, although they were to lie about what they saw. After both gave their descriptions, the other students asked the two volunteers questions about their descriptions. It was the task of the class to decide who was lying. The two volunteers listened carefully to the instructions and then discussed the task between themselves in their L1. The duration of this activity was approximately 15 minutes, with two sets of volunteers participating in the activity. Larry afterwards stressed the importance of listening for detail. He also used the pad to explain some of the vocabulary that had been met with confusion during the activity, presenting compound nouns and related words.

This concluded the two hour class. Larry praised the students and dismissed them. Many quickly left to attend mass, while others lingered to speak with Larry.

After class I spoke with Larry about his involvement with the program. $\mathrm{He}$ originally had tutored the priest of the church, and later established the classes to fulfill his practice teaching requirement with the PSU TESOL program. Larry's prior teaching experience was in mycology. He was particularly interested in the ethnic 
group he was currently teaching, and he and his wife planned to move to the students' native country after finishing school. He had arranged to teach ESL there, and would be leaving in June.

Overall, this class had a calm and relaxed atmosphere. Instruction was almost entirely in English, and a good deal of English speech was elicited, although the medium of communication among students was their L1.

Organization Y

Background Program Information. Organization $\mathrm{Y}$, unlike most of the organizations in Group II, was a social service organization which provided multiple services to its clients who were primarily low income residents of the neighborhood. It was classified in Group II since the coordinator of the ESL program worked from his home, and worked relatively independently from the organization, only contacting one of the employees of the organization periodically, and using their facilities to hold classes. ESL services were not monitored or coordinated through the organization, and the interview was conducted with the lead teacher of the program. Unknown to the researcher, this organization was in a period of transition at the time that the coordinator interviews were being conducted. Numerous telephone messages with the lead teacher were finally answered, and it was found that the lead teacher had resigned from his duties. The researcher was referred to another teacher, Richard, who had assumed the responsibilities.

At the time of the interview, the organization had been providing ESL services by means of classes for approximately one year. Reportedly, 8 to 10 students were being served, and it was estimated that students attended classes for a period of two months to a year, although this was difficult to estimate due to the newness of the program, and also to the open entry/open exit policy. Initial evaluation was reported to be done by assessing pronunciation while the students were reading aloud. Written 
tests were never given, and students' educational progress was reported to be tracked by questioning students and evaluating their answers. The long term objectives of the program were stated to increase the number of students, to be more effective in reaching people in the community, and to have classes more frequently. Organization Y expressed strong satisfaction with their method of tracking volunteers, satisfaction with their student assessment techniques, method of tracking students' educational progress and method of recruiting volunteers, and dissatisfaction with their methods of students recruitment and their volunteer training practices.

At the time of the interview, the organization had three volunteer teachers, recruited by the original coordinator. They had all been involved in the program for approximately 3 to 4 months and planned to continue. The desirability to know at least a small amount of the student population's L1 was cited as the criteria for new volunteers, and training was not provided.

Organization $\mathrm{Y}$ reported teaching predominantly by conversation means and L1/English dialogues, provided by the teachers. Tapes, children's stories and newspapers had been tried, but it was found that the students' proficiency levels were too low for these types of materials.

Classroom Observation. Classes were held once a week for $11 / 2$ hours. On the first morning the researcher was scheduled to observe, she was met at the door by Richard, who was very sick with influenza. He had contacted all of the students he was able to in order to cancel class. One student did arrive, and he tutored her. The observation was rescheduled, in order to observe a more typical class situation. The next week, four students arrived, but there were again no teachers present. The researcher was later telephoned by Richard. It was found that he was still ill, and had not contacted anyone to cancel class. The observation was again rescheduled for the following week. 
The researcher arrived the following week to find two teachers and no students. It was agreed by the teachers that they would wait for $1 / 2$ hour to see if any students arrived. Richard and the other teacher, Jack, discussed the possibility that due to the unannounced cancellation last week, perhaps no students would attend. Twenty minutes later, the student who had attended on the first scheduled session of the observation arrived.

Classes were conducted at one end of a large beige community room with 10 tables surrounded by folding chairs. It was a bright room, clean and comfortable. At the other end of the room there were vinyl chairs and a television. Attached to the room was a kitchen with coffee pots, a microwave, and other kitchen supplies.

Jack began the lesson by opening a large old volume of stories written in the student's L1. He read aloud in the L1, and the student and he worked together to translate it into English. As they came to idioms and unusual English structures in the translation process, they discussed these points. The first structure discussed was the use of the present perfect in "I haven't seen her since last year". The meaning of this sentence was explained. The next topic was the difference between "fifteenth" and "fiftieth." Jack worked with pronunciation on these two words.

Translation continued until the topic of President's Day was brought up, and a discussion ensued of this holiday, why and when it was celebrated, and also a brief explanation on Martin Luther King Day was given. The student at this point asked again about ordinal numbers, their meaning and form. At first, Jack was not certain what information the student was requesting, and explained the numbering system of the streets and avenues of Portland. The student restated her question, and Jack explained the rules of forming ordinal numbers by writing them on a piece of paper next to their corresponding cardinal numbers. This was effective, and the student appeared to understand. She wrote notes in her notebook. 
The student and Jack continued in this manner, although they switched to a new text. This time, the story was about a cap gun. Various vocabulary was explained, and also differing English structures were compared to the L1. Richard listened carefully throughout the session, and occasionally interjected an explanation or comment. It was obvious that both teachers had studied the L1 grammar, as when they were discussing the $\mathrm{L} 1$ forms, they use such terms as "diminutive," "generative," and "instrumental." Approximately 40 minutes later, the three of them discussed the student's progress in English. The student stated that she didn't understand much in English. They gave her words of encouragement, and said that if she wanted to learn, she would.

The next topic of discussion was taxes. The student asked for aid on completing her tax returns. Jack told her that if they were complicated, the AARP would do them for free. She explained that her taxes were quite simple, and Jack offered to do them for her. She in turn offered to pay, but he refused. He then told her that he believed that it was important to help people, so that they could become part of the community. They made arrangements to do her taxes the next week.

The discussion shifted to family, and the three of them shared information about their family life. Richard showed pictures of his children.

Following the discussion, Richard began to teach. He used copies from a book of dialogues. This book contained "everyday" common dialogues written in English and then translated into the student's L1. Each chapter was based on a topic such as Asking for Directions, and Getting Acquainted. The topic presented this day was "Preparing For a Job Interview." The student read the title aloud and then pointed to the wall and asked Richard what the vocabulary word was for "wall jack." She then related a story of trying to have her phone repaired, but not being able to communicate with the phone people in order to convey her problem. This settled, she continued 
reading aloud. Richard did not correct her pronunciation unless the student specifically asked for instruction on a particular word.

The reading led into a discussion of working. The student expressed frustration that she was unable to do the same work here as she had done in her home country. She then related the story of a friend of hers who was refused a job because of her poor English. There was no response to this. She resumed reading, and approximately 10 minutes later, class was over.

Richard was recruited as an ESL teacher by the original coordinator/lead teacher of the program. He was interested in the culture and language of his students, and planned to travel to their country within the year. Both he and Jack had studied and wish to continue studying the student's L1. Although he has access to other ESL materials, Richard preferred to use the translated dialogues used during the observed session. In addition to the book used for the observation, he also had purchased from a local bookstore other similar dialogues. Unlike the above noted one which is written in English with translation to the L1, the others were L1/English. During the session, the student showed the two teachers a copy of an ESL text on idioms which she had borrowed from the Lifelong Learning Center at the Multnomah County Library. The teachers commented that idioms were a good thing to study and that it appeared to be a good book. No attempt was made to incorporate this material into the lessons.

Perhaps due to the recent illness of the teacher and the confusion of canceling the previous two weeks, this class lacked the vitality of the other classes observed. The use of readings as a catalyst for discussion could have been an effective approach to teaching, but it appeared that the student desired additional means of learning English. Instead, classes seemed to be viewed by the teachers as a time to share one another's cultures and languages. 


\section{SUMMARY}

Of the 14 organizations which participated in this study, the majority of ESL programs were found to have been in operation for three years or more. One on one tutoring followed closely by classroom instruction were the most common types of services offered. Class location varied by type of organization and student needs, ranging from community rooms in the given organization, to instruction within the student's home. The majority of instructional materials used were chosen and provided by the teachers/tutors, and these included published ESL materials, as well as translated texts and realia such as newspapers, and telephone books.

An estimated 428 students were being served in this sector of the community, and it was indicated that the majority of organizations served students who attended an average of less than nine months. Student recruitment was most commonly done through word of mouth or by referrals and refugee assignment. The majority of organizations had no formal means of evaluating their students' initial English abilities, nor of tracking their students' educational progress.

The total number of volunteers reported to give ESL instruction in this sector of ESL providers was 185 with $17 \%$ defined as teachers, and $83 \%$ defined as tutors. The total student/volunteer ratio was estimated at 2.31:1. Volunteers were estimated to serve an average of three to six months in Group I, although in Group II the average was much higher, reportedly over one year. Volunteers were most commonly recruited by word of mouth, and the most common criterion for new volunteers stated by both groups was the display of desirable motivational traits such as willingness, patience or ability to commit. Volunteer training practices were conducted by a variety of means, most commonly through the use of distributing written material, and by employing the 
services of outside training personnel. The majority of organizations tracked their volunteers by maintaining a call list, and periodically phoning the volunteers.

When asked to rate program practices to program objectives, overall ratings from both groups, ranked from strongest agreement that program practices well-suited program objects to least agreement were as follows: tracking volunteers, recruiting students, recruiting volunteers, student assessment techniques, training volunteers, and tracking students' educational progress. The last three areas were all rated on an average as slightly lower than agreement.

When asked to rank the relative value of support services made available from most valuable to not at all valuable it was found that the services perceived most valuable were tutor training seminars and instructional material recommendations. Next were grant and funding information and recruitment of volunteer tutors. Last were the recommendations on methods of student evaluation, which were rated as less than valuable.

It was noted through classroom observations that the classes were as varied as the teachers who conducted them. Those teachers observed all had an appreciation and interest in the ethnic origins and native language of the students they taught. They were also motivated by a wish to help others within their community. Teaching methods were also seen to vary greatly, and it was noted that techniques including structured drilling, translation of $\mathrm{L} 1$ to English, guided and free conversation were all employed. 


\section{CHAPTER V}

\section{CONCLUSION}

Chapter 5 concludes this report by discussing some of the more significant findings in conjunction with information obtained from a review of the literature by reviewing each of the original research questions on which this study was based. Following this are five general recommendations directed toward those involved in adult ESL literacy education. The report closes with suggestions for further research.

\section{DISCUSSION OF RESULTS}

\section{$\underline{\text { Research Question Number } 1}$}

What are the non-profit organizations providing general adult ESL instruction in Multnomah County, Oregon?

It was found that 14 non-profit organizations within Multnomah County, Oregon provided general adult ESL instruction. Of these 14, 12 wished to be included on a mailing list, and 9 organizations expressed interest in meeting other ESL service providers. It was noted that there was a difference in the two groups categorized within this study as Group I and Group II. Those organizations offering ESL services in addition to other social services (categorized for the purpose of this study as Group I), were frequently aware of at least a portion of the services offered within the area. Likewise, they were known to be in existence by PCC and the Portland Literacy Council. Those organizations operating relatively independently (categorized as Group II), were not as well linked to the other service providers within the area. This would indicate that organizations operating as those in Group II have less opportunity to 
benefit from the services provided by the current adult ESL education structure within the Multnomah County area. An effort must be made to identify new programs and include them in the network of communication dissemination in order for the students attending programs such as those in Group II to benefit from the support services offered by the adult ESL system within Multnomah County, Oregon,.

As a result of this study, more organizations are now included in the mailings generated by the Portland Community College (PCC) Volunteer Tutoring program, and the Portland Literacy Council. The Portland Literacy Council publishes a newsletter which includes information on training seminars, tutor recognition functions, and other information relevant to the operation of adult ESL programs. This information will be received by the participating organizations. It is hoped to be a source of increased communication and a catalyst for networking.

\section{Research Question Number 2}

What are the nature and characteristics of these adult ESL education programs, including methods of recruiting, assessing and tracking students?

Within this sector of ESL service providers, over 400 students were reported to be served. Methods of student recruitment were most commonly by word of mouth and referral or refugee assignment. This would indicate that the reputation of a program is a prime factor in recruiting new students, and that successful management of an ESL program is one of the most valuable recruiting tools.

Initial student assessment was reported by only four organizations to be done by tests, and in two programs by coordinator interviews. Other methods such as "informal means," "self-assessment," and "the responsibility of the volunteer," indicate that the coordinators had little knowledge of the activities being conducted in the areas of student assessment of abilities and needs. Coordinators rated their program's student 
assessment practices at 2.30 on a 5 point scale, indicating only slightly less than satisfaction with their practices, and information on student evaluation was the only support service perceived as less than valuable. It would therefore appear that student assessment is not viewed as an important element of ESL education within this sector.

A review of the literature indicates that student assessment of language abilities and goals is one of the most crucial factors in providing successful ESL services (see, for example, Adult Literacy \& Basic Skills Unit, 1985; Guth \& Wrigley, 1992; McKay \& Weinstein-Shr, 1993). Students study English for a variety of reasons and possess a variety of abilities. Lack of knowledge of this information creates a situation in which the agenda of instruction is dictated by the volunteers and not by the students. Within a tutoring situation, students' language abilities and goals can be made more apparent through time. In a classroom situation, this information becomes very difficult to obtain without established procedures to elicit it. Initial attention to the needs and abilities of new students is important in order to provide services consistent with the needs of the students, and also to successfully introduce new students into the program in order to retain them.

It was also found that very little tracking of student's educational progress was conducted. Only three organizations did so by tests or student journals. Other responses such as "no formal method," "volunteer responsibility," and "selfevaluation," would indicate that the program coordinators had little knowledge of the methods of tracking students and their educational progress. This was reflected in a rating of the least satisfaction of practice to program objective. The absence of recording progress creates a situation in which it is difficult for students and volunteers to measure the results of their efforts. In some instances, progress may be apparent in the ability to better negotiate daily situations, but often language learning occurs in small, difficult-to-detect increments. In addition, if it is a program objective to 
improve the English abilities of the students attending, tracking progress must be performed in order to evaluate the effectiveness of that goal.

Research Question Number 3

What are the methods of recruiting, training and tracking volunteer teachers?

Approximately 185 volunteers were estimated to be providing ESL services in the studied sector of ESL service providers, and all instruction was done so on a volunteer basis. This creates a unique situation in program management. The most common means of recruiting volunteers was by word of mouth. As with student recruitment, the reputation of a given program is a primary recruiting tool by which volunteers may generate additional volunteers. In order to do this, coordinators must provide the necessary framework to allow volunteers to succeed. This includes proper training and tracking of volunteers.

A review of the literature found that initial volunteer interviews with the coordinator are recommended in order to provide an orientation and initially train new volunteers. This is an opportunity to clearly state what is expected of the volunteer, and in turn, what he/she can expect (Byron, 1974; Miller, 1983). A sound knowledge of expectations provides a basis from which new volunteers can understand how to proceed with their duties. The majority of organizations interviewed did conduct an initial volunteer interview.

It was also found within this study, that the most common criteria for engaging the services of a new volunteer were positive personality traits such as willingness, sensitivity, or interest. As a coordinator, it is important to determine if the volunteer's motivations are compatible with the objectives of the program. Miller (1983) presents a list of motivations for volunteering which includes gaining experience leading to a paid job or college degree, and pursuing a personal interest. Those volunteers who are 
doing so in order to advance their own careers, will generally tend to be primarily volunteering for personal gains, and often will be available only until their own goals are met. This has a potentially detrimental effect upon a program, especially if program management cannot facilitate a smooth transition from one volunteer to the next. Ultimately, the student suffers if this transition occurs and is not successfully managed. Second, if a volunteer wishes to teach or tutor in order to improve their own language skills in the student's native language, this again could be potentially detrimental to the student. Although volunteers may view the tutoring/teaching situation as a time for language exchange, the literature suggests that students value the time spent as a time to learn English. If the volunteer is motivated by the desire to improve their own second language, a conflict of interest may occur. Both of these situations can be monitored by strengthening the criteria for new volunteers, and ensured through successful volunteer coordinator interviews.

It was found that organizations used a variety of means of training, but most commonly reported were outside on-site training services such as with Oregon Literacy or PCC, and by giving volunteers prepared handouts. Equally commonly reported was a response of no training at all. Many volunteers come to an organization with little or no teaching experience, and initial contact with students can often be an intimidating situation for a new teacher/tutor. Training volunteers offers them the ability to provide competent services and to succeed. Not only must volunteers be culturally sensitive, and have a working knowledge of the language, they must understand the importance that students place on learning English, and value and manage wisely the time that is shared between volunteer and student. Coordinators rated their volunteer training practices to program objectives at slightly below satisfaction. They perceived volunteer training as one of the most valuable support services made available. 
Tracking volunteers in this sector of service providers was normally done by telephone contact, or by no formal means at all. Given the number of volunteers within each organization, tracking was done accordingly. Coordinators indicated strong satisfaction in this area of program management.

\section{Research Question Number 4}

What, if any, ESL resource services made available would be perceived as most beneficial to this sector of the ESL instructional community?

The finding of this study indicated that Groups I and II had differing opinions on the values of various support services offered. As explained in Chapter 3, the organizations in Group I are characterized as organizations providing multiple social services to their clients, with ESL included as one of these services. The organizations in Group II are characterized as ESL service providers relatively independent of the organization under which they are headed. Within Group II, only volunteer recruiting was rated as valuable, while all others were less than valuable. Within Group II, although the total number of volunteers was much less than in Group I, volunteers were reported to stay on an average over one year. It is speculated that this creates a situation in which the importance of other support services such as training and material recommendations are reduced due to low volunteer turn-over. But this situation also increases the need for recruiting due to the difficulty of recruiting volunteers able to make a long-term commitment. On the other hand, within Group I, volunteers remain with a program on an average of 3 to 9 months. Volunteer training and material recommendations were both rated as valuable, whereas volunteer recruiting was perceived as less than valuable. For those organizations within Group II, the supply of volunteers appeared not to be as much of an issue as the ability to train and provide them with teaching materials. 
Volunteer training and material recommendations were overall rated highest, followed closely by volunteer recruiting, and grant and funding information. Of the five support services mentioned in the coordinator interviews, only one service, student evaluation, was rated less than valuable.

\section{RECOMMENDATIONS FOR PRACTITIONERS}

Based on the results from this study and a review of the literature, the following recommendations are made. These recommendations are directed toward all individuals and groups involved in the education of adult ESL literacy students.

1. Provide a framework in which volunteers can succeed. This can be done by initially stating clear program objectives, making understood what is expected of and by the volunteer, and providing adequate training.

2. Strengthen the criteria for new volunteers. Determine that the volunteer's motivations are compatible with the students' needs. This can be done by understanding what the students expect from the language program, defining the objectives of the language program, and recruiting volunteers whose motivations will coincide with the objectives of the students and the language program.

3. Improve methods of student assessment. If we are truly to work toward a learner-centered environment, we must promote the necessity for student assessment, create assessment tools suitable to the informal atmosphere of non-profit programs, and train volunteers in the advantages of their use and how to implement them.

4. Promote literacy education. A major question throughout this research has been, "Why are these ESL programs categorized under ESL literacy education?" From an historical perspective, English language education and literacy education have been grouped together and only recently have they been considered separate fields in adult education. In addition, The National Literacy Act of 1991, which has provided a 
substantial increase in federal funding for adult education, defined literacy to be the ability to read, write, and speak in English. Therefore, funding is provided for both Adult Basic Education and ESL under this heading.

Those programs studied throughout the research provided relatively little literacy instruction, focusing mainly on conversation, i.e. listening and speaking. Of the literacy approaches discussed in the review of the literature within this study, only two of the discussed approaches were noted during the classroom observation. Organization $\mathrm{C}$, influenced by the Laubach method of literacy education, taught literacy education through the Phonics approach. Organization G exhibited a form of teaching Spelling during the vocabulary session when presenting the contrastive analysis of spelling and pronunciation of four English consonant sounds. The other two organizations observed did not exhibit any specific instructional approaches to teaching reading and writing. It is unknown whether this was due to a lack of ability and knowledge in how to teach reading and writing, or due to an idea that written skills are not as important as oral skills. In either case, if we are to be a society which views literacy as a basic right of its members, the importance of literacy education must be promoted, methods of literacy education must be taught and implemented, and funding must be provided to insure that ideas can be put into successful practice.

5. Lobby for additional support to increase the resources for adult ESL education. It would seem that with strengthened communication and organization between the service providers, a set of solutions to many of the common problems could be developed, adapted and adopted. Yet, the limitations of time, money, and adequate training may inhibit these efforts. Only 6 organizations of the 14 who participated in the study employed a paid coordinator, and in those 6 instances, the coordination of the ESL program was only one of many responsibilities held. 
McKay (1993) states that "a society that depends on volunteers to address the issue of literacy does not view literacy as a basic right of its members" (p. 40). The observation of Organization $Y$ yielded a statement from one of the volunteers which reflects a common belief that the individuals involved are responsible for the problems within literacy education. The volunteer was observed to say to the student that if she wanted to learn English, she would. This statement suggests that the volunteer believes that the student's ability to learn English lies in her desire to do so. But is this really the case? Obviously this student has a strong desire to learn. She attends her weekly class, knowing that it may be canceled without notice. She brings to class resources which she has discovered through inquiry at the public library. Unfortunately, regardless of the strength of desire that she may have to learn English, she is not within a system which values adult literacy education enough to provide her with consistent classes convenient to her schedule, and trained teachers able to use the materials she herself has found. Within the current structure, one that depends on volunteers to address the literacy issue, many students cannot be provided with the services necessary to meet their needs.

Guth and Wrigley (1992) studied model programs throughout the nation and found that no programs, even the most successful ones, were able to be uniformly excellent in all of the program components upon which they were evaluated. They believed it to be unrealistic to expect a program to excel in all facets of its operation given the current resources available to ESL literacy programs.

Within the United States one can find a large body of literacy research and a development of recommendations for successful practices. In addition, there is a structure in place aimed at delivering this information. Increased communication and dissemination of this information is a step towards improving practices within the current structure, but it is a relatively futile attempt if there are not trained people to 
use the materials, and sufficient compensation for those that are providing ESL services. If we believe literacy to be a basic right of the members of our society, we must lobby and obtain the necessary resources to allow the educational process to occur.

\section{SUGGESTIONS FOR ADDITIONAL RESEARCH}

This study has attempted to identify and describe the non-profit organizations within Multnomah County, Oregon which provide adult ESL literacy education. A list of non-profit organizations has been generated from this research, in addition to a description of general program characteristics and practices, and information as to the perceived value of various support services offered. This preliminary research exposes areas which require additional study.

Non-profit organizations attract some of the most difficult-to-reach literacy students (Irwin, 1991). A significant number of students within Multnomah County, Oregon are being served in the non-profit sector, and students are regularly attending these types of programs. There is much to be learned as to what these programs offer that are lacking in the public programs. Investigation of the program characteristics which attract students to this type of organization would be beneficial to all sectors of ESL service providers.

Findings from this study also indicated that relatively little reading and writing instruction was provided, giving more attention to speaking skills. Research needs to be conducted in order to determine if the cause is a lack of student interest, or a lack of ability by service providers to address this area of ESL education.

Within the scope of the present study, data was inconclusive as to the determination of the philosophical underpinnings as discussed by Wrigley (1993). It is speculated that the majority of the organizations within this study are operating under 
both the Social and Economic Adaptation philosophy and the Common Educational Core philosophy. As discussed in Chapter 2, the Social and Economic Adaptation orientation views the function of ESL literacy education as supplying the students with skills necessary to meet their critical economic needs, the needs of the community, and the needs of society as a whole. A Common Educational Core orientation strives to prepare students to succeed in the existing educational systems, for example to pass the GED test, or to be prepared to enter into vocational or academic programs. A more indepth study should be performed in order to better understand under which philosophical underpinnings the local organizations are operating. In addition, other characteristics of non-profit organizations need to be analyzed in greater detail, to be able to design materials and assessment instruments which better suit organizations staffed entirely by volunteers working in a less formal environment than those educational programs within the public sector.

\section{SUMMARY}

The preceding report was designed and conducted to identify and describe those ESL service providers believed to be less formally linked to the federal, state, and local ESL service structure. It was motivated by the researcher's belief that the diverse nature of ESL programs is an asset, yet information on all levels must be shared in order to be able to choose with discrimination, and implement those practices which best serve the needs of the student population. It is hoped that the information generated from this report will facilitate communication, and improve ESL services to better meet the needs of the community. 


\section{REFERENCES}

Adult Literacy \& Basic Skills Unit. (1985). ESL/literacy: an introductory handbook for tutors. London: Author.

Auerbach, E. R., \& Burgess, D. (1985). The hidden curriculum of survival ESL. TESOL Quarterly, 19(3), 475-495.

Brewer, K., \& Taran, P. (1992). Manual for Refugee Sponsorship. (Available from Public Information Office of the Immigration and Refugee Program of Church World Services, Church World Services/Immigration and Refugee Program, 475 Riverside Drive Room 656, New York, NY 10115)

Brown, H. D. (1991). Vistas: An interactive course in English. Englewood Cliffs, NJ: Prentice-Hall.

Byron, E. S. (1974). Recruiting and training of volunteers. In J. G. Cull \& R. E. Hardy (Eds.) Volunteerism: an emerging profession (pp. 33-63). Springfield, IL: Charles C. Thomas.

Cook, W. (1977). Adult literacy education in the United States. Newark, DE: International Reading Association.

Cortright, R. W. (1961). Professional preparation in literacy education. Journal of Teacher Education, 16, 290-293.

Crandall, J. (1993). Professionalism and professionalization of adult ESL literacy. TESOL Quarterly, 19(3), 475-495.

Flemming, D. (1984). English as a second language in Northern New England: The state of the art 1984. (Report No. FL 014 827). Keene, NH: Keene State College. (ERIC Document Reproduction Service no. ED 253 087)

Graff, H. (1979). The literacy myth: Literacy and social structure in the nineteenthcentury city. New York: Academic Press.

Guth, G. J., \& Wrigley, H. S. (1992). Adult ESL literacy programs and practices. a report on a national research study. (Report No. FL 800 571) San Mateo, CA: Aguirre International. (ERIC Document Reproduction Service No. ED 348 895)

Haines, D. W. (1985). Toward integration into American society. In D. W. Haines (Ed.) Refugees in the United States: A reference handbook (pp. 37-55). Westport, CT: Greenwood.

Heath, S. (1983). Ways with words: Language, life, and work in communities and classrooms. Cambridge: Cambridge University Press. 
Irwin, P. M. (1991). National Literacy Act of 1991: Major provisions of PL 102-73

(CRS Report for Congress). Washington, DC: Congressional Research Service. (ERIC Document Reproduction Service No. ED 341 851)

Klassen, C., \& Burnaby, B. (1993). "Those who know": Views on literacy among adult immigrants in Canada. TESOL Quarterly, 27(3), 377-398.

McKay, S. (1993). Agendas for second language literacy. Cambridge: Cambridge University Press.

McKay, S., \& Weinstein-Shr, G. (1993). English literacy in the U.S.: National policies, personal consequences. TESOL Quarterly, 27(3), 399-420.

Miller, J. M. (1983). ABE/ESL volunteer program organizational handbook. (Report No. CE 036 523). Seattle, WA: Washington Literacy, Seattle. (ERIC Document Reproduction Service No. ED 232 039)

Molinsky, S., \& Bliss, B. (1989). Side by side. Englewood Cliffs, NJ: Regents/Prentice Hall

National Literacy Act of 1991, PL 102-73, Sections 2 \& 3, 105 stat. 333.

Nelson, D. \& Bringewatt, M. (1986). Report on the evaluation of adult refugee ESL programs in Minnesota. (Report No. FL 800 227). St. Paul, MN: Minnesota State Department, Office of Community and Adult Basic Education. (ERIC Document Reproduction Service No. ED 322 800)

Olsen, R. (1994). LEP enrollment statistics. TESOL Matters, 4(1), 12-13.

Parnwell, E. C. (1989). The new Oxford picture dictionary. Oxford: Oxford University Press.

Pelavin Associates. (1991). Study of ABE/ESL instructor training approaches: state profiles report (Contract No. VN90001001). Washington, DC: San Francisco State University (ERIC Document Reproduction Service No. ED 338 605)

Rowekamp, J. (No Date). Adult ESL: definition and program design. Unpublished manuscript submitted as a Plan B paper to the University of MN ESL M.A. program.

Smith, M. (1991). Handbook for refugee sponsorship. (Available from Sponsors Organized to Assist Refugees, 5404 N.E. Alameda Drive, Portland, OR 97213)

Street, B. (1984). Literacy in theory and practice. Cambridge: Cambridge University Press.

Tollefson, J. W. (1988). Covert policy in the United States refugee program in Southeast Asia. Language Problems and Planning, 12(1), 113-132.

Tollefson, J. W. (1991). Planning language, planning inequality: language policy in the community. New York: Longman. 
Wiley, T. (1993). Discussion of Klassen \& Burnaby and McKay \& Weinstein-Shr: Beyond assimilationist literacy policies and practices. TESOL Quarterly, 27(3), 421-430.

Wrigley, H. S. (1993). One size does not fit all: Educational perspectives and program practices in the U.S. TESOL Quarterly, 27(3), 449-466.

Wrigley, H. S., Guth, G. J. (1992) Adult ESL literacy: State of the art 1990. (Report No. FL 800 569) San Mateo, CA: Aguirre International. (ERIC Document Reproduction Service No. ED 348 893) 
APPENDIX A

MAILING LIST OF PARTICIPATING ORGANIZATIONS 


\section{APPENDIX A \\ MAILING LIST FOR PCC VOLUNTEER TUTORING \& PORTLAND LITERACY COUNCIL}

As of 2/23/94

(Unless noted, all organizations are interested in meeting with others)

\section{BRIDGE SCHOOL}

1231 S.W. Morrison

Portland, OR 97205

228-5657

Contact: Sharon Reed
Literacy Projects for homeless

Including GED, ESL, \& ABE

Serving variety of ethnic populations.

NOT INTERESTED IN MEETINGS

\section{CALVARY LUTHERAN CHURCH}

c/o Anne Flego

6032 S.E. Woodward

Portland, OR 97206

771-2409
Serving students from the former USSR, although students from any ethnic groups are welcome.

\section{CATHOLIC RESETTLEMENT SERVICES}

5404 N.E. Alameda Drive

Portland, OR 97213

249-5892

Contact: Joy Brandt
Refugee resettlement program

Serving a variety of ethnic populations

\section{CHINESE SOCIALIZATION CENTER}

4937 S.E. Woodstock Blvd.

Portland, OR 97206

771-7977

Contact: Robert Sang
Variety of programs including Adult ESL, bilingual ed. for children, mental health, and ESL video tape program.

Serving mainly Chinese \& Vietnamese.

\section{ENGLISH SPEAKING UNION/ENGLISH IN ACTION PROGRAM}

1314 S.E. Birch

Portland, OR 97214

232-7745

Contact: Charlotte Wirt
One program of the English Speaking Union.

Mainly conversation to students from a variety of ethnic backgrounds.

Students must have some prior English abilities. 
HISPANIC ACCESS CENTER

123 N.E. 3rd, Room 336

Portland, OR 97232

236-9670

Contact: Odalis Perez
One of a variety of services to aid low income Hispanics adults.

LUTHERAN FAMILY SERVICE 605 S.E. 39th

Portland, OR 97214

233-0042

Contact: Jode Horn

Refugee resettlement Volag

Serving mainly former USSR and

Vietnamese adult.

PORTLAND IMPACT

c/o Bob Kopp

6107 N.E. 14th

Portland, OR 97211

288-7900

SAINT PATRICK'S CHURCH c/o Apolonia Ponce

6830 S.W. 15th Avenue

Portland, OR 97219

246-8957

Serving predominately low-income adults from the former USSR.

Predominately serving Hispanic adults in the capacity of initial language skills with the goal of accessing other educational programs.

Serving Polish adults.

\section{ST. STANISLAUS CHURCH}

$3916 \mathrm{~N}$. Interstate

Portland, OR 97227

Contact: Father Richard

NOT INTERESTED IN MEETINGS

Philliposki

\section{SPONSORS ORGANIZED TO ASSIST REFUGEES (SOAR)}

5404 N.E. Alameda Dr.

Portland, OR 97213

284-3002

Contact: Chris Boberg

Refugee resettlement Volag

Serving variety of refugee

populations and Hispanics.

\section{TIBETAN-UNITED STATES} RESETTLEMENT PROJECT

2946 N.E. 108th Avenue

Portland, OR 97220-2703

255-5553

Contact: David Alloway

Immigrant resettlement project

Serving Tibetan adults in a variety of resettlement functions including E.S.L. tutoring. NOT INTERESTED IN MEETING. WOULD LIKE INFORMATION ON GED 